\title{
Real-Time Effects of Central Bank Interventions in the Euro Market
}

Fatum, Rasmus; Pedersen, Jesper

Publication date:

2007

Document version

Publisher's PDF, also known as Version of record

Citation for published version (APA):

Fatum, R., \& Pedersen, J. (2007). Real-Time Effects of Central Bank Interventions in the Euro Market. Economic Policy Research Unit. Department of Economics, University of Copenhagen. 


\title{
EPRU Working Paper Series
}

Economic Policy Research Unit Department of Economics University of Copenhagen Studiestræde 6

DK-1455 Copenhagen $\mathrm{K}$ DENMARK

Tel: (+45) 35324411

Fax: (+45) 35324444

Web: http://www.econ.ku.dk/epru/

Real-Time Effects of Central Bank Interventions in the Euro Market

\author{
Rasmus Fatum \\ Jesper Pedersen
}

ISSN 0908-7745 


\section{Real-Time Effects of Central Bank Interventions in the Euro Market}

This version: March 16, 2007

Rasmus Fatum*

School of Business

University of Alberta

Edmonton, Alberta

Canada, T6G 2R6

Email: rasmus.fatum@ualberta.ca
Jesper Pedersen

University of Copenhagen and

Danmarks Nationalbank

DK-1093 Copenhagen K

Denmark

Email: jesper.pedersen@econ.ku.dk

Abstract: $\quad$ This paper investigates the real-time effects of foreign exchange intervention using official intraday intervention data provided by the Danish central bank. Denmark is currently pursuing an active intervention policy under the provisions of the Exchange Rate Mechanism (ERM II) and intervenes on a discretionary basis when considered necessary. Prior participation in ERM II is a requirement for adoption of the Euro. Therefore, our study is of particular relevance for the new European Union member states that are either currently participating in ERM II or expected to do so at a later date as well as for Denmark. Our analysis employs the twostep weighted least squares estimation procedure of Andersen, Bollerslev, Diebold and Vega (2003) and an array of robustness tests. We find that intervention exerts a statistically and economically significant influence on exchange rate returns when the direction of intervention is consistent with fundamentals and intervention is carried out during a period of high exchange rate volatility. We also show that the exchange rate does not adjust instantaneously to the unannounced and discretionary interventions under study. We conclude that intervention can be an important short-term policy instrument for exchange rate management.

Key words: Foreign Exchange Intervention; Intraday Data; ERM II

JEL Classifications: D53; E58; F31; G15

* Corresponding author. Fatum is also a member of the Economic Policy Research Unit (EPRU) at the University of Copenhagen. Fatum gratefully acknowledges financial support from a J.D. Muir grant. We are grateful to Danmarks Nationalbank for providing the official intraday intervention data. We thank seminar participants at Danmarks Nationalbank for very valuable comments and discussions, in particular Kim Abildgren, Jesper Berg, Karsten Biltoft, Anders Møller Christensen, Hugo Frey Jensen, Frank Nielsen and Peter Storgaard. The views expressed do not necessarily reflect the views of Danmarks Nationalbank. 


\section{1.}

\section{Introduction}

This paper investigates the real-time (intraday) effects of Danish central bank intervention in the Euro (EUR) market. ${ }^{1}$ The interventions under study are carried out under the provisions of the Exchange Rate Mechanism (ERM II). Proprietary data on official, intraday intervention transactions, provided by the Danish central bank (Danmarks Nationalbank, henceforth DN), facilitates our investigation. Our investigation employs the time-series econometrics of Andersen and Bollerslev (1998) and Andersen, Bollerslev, Diebold and Vega (2003).

Our motivation for assessing the intraday effects of DN intervention is two-fold. First, prior successful participation in the ERM II is a requirement for joining the European Monetary Union (EMU) and for adoption of the EUR. The current Danish ERM II exchange rate management experience can, therefore, provide important insights and normative policy recommendations of particular relevance for Denmark and the 6 new European Union (EU) member states that are currently participating in the ERM II. Similarly, our study seems to have particular relevance for potential EU candidate countries as well as the 5 new EU member states that are expected to participate in the ERM II at a future date. ${ }^{2}$

Second, it is very rare that a central bank makes available official intraday intervention data. In fact, until now only the Bank of Canada and the Swiss National Bank have made such data available. ${ }^{3}$ It has, however, been more than 8 and 11 years, respectively, since the Bank of Canada and the Swiss National Bank last intervened. By contrast, Denmark is currently pursuing an active intervention policy and intervenes on a discretionary basis when considered necessary. The DN intraday intervention data, therefore, constitutes a unique opportunity to learn about the

\footnotetext{
${ }^{1}$ See Humpage (2003), Neely (2005), and Sarno and Taylor (2001) for recent surveys of the intervention literature.

${ }^{2}$ Denmark and the new EU member states Cyprus, Estonia, Latvia, Lithuania, Malta, and Slovakia currently participate in the ERM II; the new EU member states Bulgaria, The Czech Republic, Hungary, Poland and Romania do not. Slovenia joined the EMU on 1 January 2007.

${ }^{3}$ The Swiss National Bank intraday intervention data is publicly available; the Bank of Canada intraday intervention data is not.
} 
real-time effects of foreign exchange intervention carried out by a central bank that is currently intervening.

The best known studies of the now historical data from the Bank of Canada and the Swiss National Bank are the important contributions by Fischer and Zurlinden (1999) and Payne and Vitale (2003), both of which assess the effects of Swiss interventions. Fischer and Zurlinden (1999) focus on (scaled) exchange rate changes measured between consecutive interventions and use an irregular time-series model as the foundation for their analysis. They find that only initial interventions matter while subsequent interventions are ineffective. Within the context of an event study approach, Payne and Vitale (2003) find evidence of a systematic link between intervention and both exchange rate returns and volatility. In a more recent contribution, Pasquariello (2006a) also finds evidence that Swiss National Bank interventions have significant effects on exchange rate returns. ${ }^{4}$

The Bank of Canada intraday intervention data has been analyzed by Beattie and Fillion (1999) and Fatum and King (2005). ${ }^{5}$ Beattie and Fillion (1999) conduct a time-series analysis of the intraday effects of intervention and find some evidence of reduced exchange rate volatility. Fatum and King (2005) use an event study methodology and find that intervention has a significant influence on the exchange rate level, in the intended direction, and some weaker evidence of a short-lived reduction of exchange rate volatility. ${ }^{6}$

Our study employs data on official, intraday DN intervention in the Danish-Krone/Euro (DKK/EUR) foreign exchange rate market over the 1 January 2002 to 31 December 2004 time-

\footnotetext{
${ }^{4}$ In a related study, Burkhard and Fischer (2006) find evidence of intraday effects of Swiss intervention threats during the 2002 to 2005 period when no actual Swiss interventions occurred. Fischer (2003) also analyzes the official Swiss National Bank intraday intervention data.

${ }^{5}$ See D'Souza (2002) and Fatum (2006) for daily data studies of Bank of Canada intervention.

${ }^{6}$ Studies of intraday effects of intervention that use Reuters data or use additional information/assumptions regarding the intraday timing of intervention operations include Beine, Lahaye, Laurent, Neely and Palm (2006), Beine, Laurent and Palm (2003), Cai, Cheung, Lee and Melvin (2001), Chang and Taylor (1998), Chari (2006), Dominguez (2003, 2006), Goodhart and Hesse (1993), Kim (2005), Peiers (1997), and Scalia (2004). Fischer (2004) illustrates the lack of accuracy of Reuters reports in the context of Swiss interventions; Dominguez (2006) argues that it is likely that Reuters provides better coverage in the context of G3 interventions.
} 
period as well as the bid and the offer spot DKK/EUR exchange rates at the end of every 5minute interval over every 24-hour period. The latter data was purchased from Olsen and Associates. We focus our investigation on the level (exchange rate return) effects of intervention. ${ }^{7}$

In order to properly model the well-known idiosyncrasies of intraday exchange rate data while at the same time allow intervention to affect both the conditional mean and the conditional variance, we adopt the two-step weighted least squares (WLS) technique proposed by Andersen and Bollerslev (1998) and recently applied by Andersen, Bollerslev, Diebold and Vega (2003). Specifically, we obtain the residuals from a (first step) standard conditional mean model of 5minute exchange rate returns. We then use the concept of realized volatility and a Fourier flexible form with several trigonometric terms to model the intraday pattern of these residuals. Lastly, we use the fitted residuals from the second model to perform a WLS estimation of the (first step) model of exchange rate returns. In addition, we follow Andrews (1993) and test for parameter instability. We find significant evidence of one change point in our data and, as a result, we carry out the analysis on the full sample as well as separately on two sub-samples.

Consistent with the aforementioned intraday studies of Bank of Canada and Swiss National Bank intervention and consistent with the findings of Dominguez (2003), who examines the intraday effects of G3 interventions, we find statistically significant evidence that intervention affects the level of the exchange rate in the intended direction. Specifically, we find a statistically an economically significant effect of intervention when intervention is consistent with fundamentals and coinciding with a period of relatively high exchange rate volatility. Moreover, we find that it takes about 30 minutes before the exchange rate has fully adjusted to the intervention news.

As one of several robustness checks, we control for the timed announcement of other types of Danish and EUR macro news, including news regarding balance of payments, CPI, GDP

\footnotetext{
${ }^{7}$ The key goal of intervention in the context of ERM II is to ensure that the value of the currency of the ERM II member state vis-à-vis the EUR is kept within a publicly announced fluctuation band. Therefore, the level effects of intervention are of primary interest.
} 
and unemployment. We do so to ensure that our findings regarding the effects of intervention are not tainted by the coinciding arrival of other news. Inclusion of the news variables does not affect our results. As an important methodological robustness check, we follow Andersen, Bollerslev, Diebold and Vega (2003) and reassess the effects of intervention on exchange rate returns using heteroskedasticity- and serial-correlation consistent (HAC) standard errors. The HAC results are qualitatively identical to those stemming from the more sophisticated two-step WLS procedure.

The rest of the paper is organized as follows. The next section provides an overview of the institutional aspects regarding ERM II and DN intervention. Section 3 presents the data and Section 4 explains the econometric methodology. Section 5 presents the results and assesses the fit of the model. Section 6 presents several robustness checks. Section 7 discusses the main results and Section 8 concludes.

\section{Institutional Aspects}

With the launch of the EUR on 1 January 1999, the ERM II was introduced and replaced the exchange rate mechanism (ERM I) of the European Monetary System (EMS). ${ }^{8}$ According to the EU Accession Treaty, successful participation in ERM II is a requirement for joining the EMU and for adoption of the EUR. Currently Denmark as well as 6 new EU members participate in ERM II. Denmark has participated since 1 January 1999, Estonia and Lithuania since 28 June 2004, Cyprus, Latvia, and Malta since 2 May 2005, and Slovakia since 28 November $2005 .^{9}$ Bulgaria, The Czech Republic, Hungary, Poland and Romania are expected to follow. ${ }^{10,11}$

\footnotetext{
${ }^{8}$ See Brandner, Grech and Stix (2006) for a recent analysis of intervention in the EMS.

${ }^{9}$ Prior to the launch of the EUR, Denmark participated in ERM I. Denmark has since 1982 successfully maintained a stable exchange rate vis-à-vis a basket of other EMS currencies and subsequently vis-à-vis the EUR in the ERM II.

${ }^{10}$ See Disyatat and Galati (2005) and BIS (2005) for studies of intervention in emerging markets, including The Czech Republic, Hungary and Poland. See also Hochreiter and Siklos (2006) for a brief discussion of monetary policy and exchange rate issues pertaining to the new EU member states and candidate countries.

${ }^{11}$ Two old EU member states do not participate in neither the EUR nor ERM II. Great Britain is under no obligation to move to Stage Three of the EMU and does not appear to be taking immediate steps towards joining the EUR. Sweden did not join the EUR at its inception and decided to pursue a policy of inflation
} 
In ERM II, a bilateral central rate and a deviation band is set for the currency of the participating country vis-à-vis the EUR, but not against the currency of the other member states. The DKK/EUR central rate is 7.46038 and the deviation band is set to +/- 2.25 percent. All other ERM II member states maintain their respective currencies within a +/- 15 percent deviation band.

In order to keep its currency inside the deviation band, the ERM II member state adjusts its short term interest rates and/or intervenes in the foreign exchange market. If the currency reaches either the upper or the lower limit of the deviation band, both the European Central Bank (ECB) and the central bank of the member state in question intervene to maintain the exchange rate inside the interior of the band. The ECB is only obligated to intervene when a currency reaches one of the band limits. In such cases, to ensure that the finite holdings of foreign exchange reserves do not restrict the ability to intervene, the ECB and the intervening national central bank may grant each other unlimited intervention credit with an initial maturity of up to 3 months. Interest is charged on such credit, and the credit may be extended.

Usually interventions when the currency is on the limit of the deviation band are avoided. Instead, interventions are carried out when the currency is in the interior of the band. In the case of Denmark in ERM II, at no point has the Danish currency been near either the upper or the lower limit of the band (see Figure 1). Accordingly, our analysis pertains only to one-sided interventions (i.e. interventions carried out unilaterally by the DN) for which intervention credits have not been required. ${ }^{12}$

DN interventions are discretionary, unannounced and automatically sterilized. According to DN traders, half of the DN interventions carried out during the period under study were

targeting instead of ERM II participation. On 14 September 2003, Sweden held a referendum in which it was decided not to adopt the EUR and subsequently Sweden has not joined ERM II.

${ }^{12}$ The ERM II member states are not obligated to simultaneously inform or get permission from the ECB when carrying out unilateral interventions. However, the ECB is automatically informed about the interventions at the daily fixing concert involving all ERM II member states at 14.15 GMT+1 and again at the end of the business-day at 17.05 GMT+1. 
conducted by phone, i.e. the DN trader in charge of an intervention operation contacts the market counterpart directly via phone. The remaining intervention transactions were conducted through a centralized market place (broker or electronic trading platform). ${ }^{13}$

For additional details regarding the ERM II and the Danish foreign exchange rate policy see Danmarks Nationalbank (2003a), ECB (2004), and EU (2006).

\section{Data}

3.1. The Intraday Intervention Data

The intervention data covers all DN interventions in the DKK/EUR market over the 1 January 2002 to 31 December 2004 period. It includes the exact amount and time-stamp to the nearest minute obtained directly from the trade-sheet of each intervention transaction. Intervention amounts are quoted in EUR and a positive amount denotes a purchase of EUR against a sale of DKK. In accordance with the ERM II provisions, the DN trader conducting an intervention operation is obligated to write the amount and the exact time of the operation on the trade-sheet immediately after the completion of each individual intervention transaction. At the latest, this information is forwarded to the ECB by the end of the trading day. Our intraday intervention data consist of this extremely reliable information.

Table 1 displays descriptive statistics of the intervention data. ${ }^{14}$ Our sample consists of a total of 89 intervention days, encompassing a total of 220 intervention transactions. On intervention days, the average intervention amount is EUR 164 millions. A total of 68 intervention days consist of EUR purchases. Figure 1 shows that all interventions occur when the DKK/EUR rate is in the interior of the deviation band. In fact, at no point during the period under

\footnotetext{
${ }^{13}$ Unfortunately, we were unable to obtain detailed information regarding whether each individual intervention transaction was carried out by phone or via centralized trading.

${ }^{14}$ Given the confidential nature of the intervention data, we are not at liberty to display or describe this data in greater detail.
} 
study does the distance between the DKK/EUR rate and either band limit exceed the distance between the DKK/EUR rate and the central rate. ${ }^{15}$

\subsection{The Exchange Rate Data}

The high-frequency DKK/EUR exchange rate data is provided by Olsen and Associates, collected from commercial banks by Tenfore and Oanda, and covers the full 2002 to 2004 sample period. The data consists of the bid and the offer spot exchange rate at the end of every 5-minute interval over every 24-hour period.

The quotes are indicative quotes, i.e. not necessarily traded quotes. Therefore, the possibility of the data containing irrelevant quotes at which no rational investor will trade is a concern. Another concern is the possibility of our data including a keying error by a dealer. In order to take into account these concerns we follow Dacorogna, Müller, Nagler, Olsen and Pictet (1993) and filter the data for anomalies and bad quotes.

We employ exchange rate data with a frequency of 5 minutes, instead of exchange rate data with the same frequency as our intervention data, i.e. a frequency of 1 minute. It is wellknown that market microstructures such as non-synchronous trading and bid-ask bounces are likely to render econometric analysis invalid by introducing artificial statistical properties (e.g. negative serial correlation) strong enough to drown the "true" properties of the data. It is also well-known that the severity of these microstructure concerns decreases at lower frequencies. ${ }^{16}$ Therefore, instead of using the smallest frequency possible (which in this case corresponds to tick-by-tick data), we follow the standard literature and use the typical frequency of 5 minutes. For additional details see Campbell, Lo and MacKinlay (1997).

\footnotetext{
${ }^{15}$ During the 3 year period under study, the DKK/EUR exchange rate trades between 7.4150 and 7.4592 DKK/EUR. For comparison, the $+/-2.25$ percent deviation band constitutes a permissible trading range between 7.2925 and 7.6282 DKK/EUR. The mean of the DKK/EUR exchange rate across the sample period is 7.437 DKK/EUR, thus close to the central rate and far away from either band limit.

${ }^{16}$ Intuitively, the "noise" caused by the microstructures remains the same across the higher and the lower sampling frequency while the properties of the "true" process increase at the lower frequency.
} 
Following Andersen and Bollerslev (1998) and Andersen, Bollerslev, Diebold and Vega (2003), our midpoint (log) exchange rate price at each 5-minute point is constructed by linearly interpolating the average of the preceding and immediately following (log) bid and offer quotes. The continuously compounded 5-minute returns $\left(R_{t}\right)$ are calculated as the change in the 5 -minute

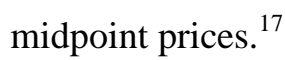

It is standard in the intraday literature on widely traded currency pairs (e.g. the USD/EUR, the USD/DEM, the USD/JPY, and the USD/GBP) to define a trading day to start at 21.05 GMT the night before and end at 21.00 GMT on the evening of the trading day in question (see Bollerslev and Domowitz, 1993) and, furthermore, to define a weekend to start at 21.05 GMT Friday and finish 21.00 GMT Sunday (see Andersen, Bollerslev, Diebold and Vega, 2003). The Danish exchange rate market, however, is markedly different from the major exchange rate markets in that there is very little or virtually no trading of the Danish currency outside of standard Danish business hours (see Danmarks Nationalbank 2003a and ECB 2004). Therefore, we define a trading day in the Danish currency market to start at $8.00 \mathrm{GMT}+1$ and finish at 17.00 GMT $+1 .{ }^{18}$ Consequently, our analysis considers a total of 752 trading days consisting of a total of 80476 5-minute DKK/EUR exchange rate returns. ${ }^{19}$ Importantly, our trading day definition encompasses all intervention transactions in the period under study.

As shown by Bollerslev and Domowitz (1993) and Andersen and Bollerslev (1998) and others, high-frequency foreign exchange data can be expected to display often complex intraday periodicities (intraday seasonality). Table 2 summarizes key statistical properties of our 5-minute returns. As expected, the returns have fatter tails than a normal distribution (with a kurtosis of

\footnotetext{
${ }^{17}$ Andersen, Bollerslev, Diebold and Vega (2003, p. 40) note that "Goodhart, Ito and Payne (1996) and Danielsson and Payne (1999) find that the basic characteristics of 5-minute returns constructed from quotes closely match those calculated from transaction prices." Transaction prices are not available for the DKK/EUR exchange rate market.

${ }^{18}$ This definition of a trading day carries over naturally to a definition of a weekend, i.e. we define a weekend to start at 17.05 GMT+1 Friday and finish at 8.00 GMT+1 Monday.

${ }^{19}$ We also deleted the following fixed holidays from the analysis: 1 January, Easter (3 holidays), Christmas (24/25/26 December), 31 December as well as 4 Denmark-specific holidays (Store Bededag, Kristi Himmelfartsdag, Anden Pinsedag, Grundlovsdag).
} 
18), and the Bera-Jarque test for normality is strongly rejected. The rejection is mainly attributed to excess kurtosis. The 5-minute return series is far from being a white-noise process due to long memory, as evidenced by the Ljung-box Q-test statistic which rejects that the first 540 autocorrelations (corresponding to one business-week) are jointly zero.

Figure 2 shows that, although the autocorrelations are small, they frequently breach the confidence bands. This long memory can be attributed to daily periodicity. The absolute returns show a periodicity through the day (with breaks, of course, due to our business hours trading day definition). ${ }^{20}$

\section{Econometric Methodology}

The previous section described DKK/EUR exchange rate data characteristics that are very similar to those found by Andersen and Bollerslev (1998) and Andersen, Bollerslev, Diebold and Vega (2003) in their analyses of high-frequency exchange rate data. Clearly, the long memory and the intraday periodicity of our exchange rate series would affect the residuals of a standard OLS regression of interventions on exchange rate returns, thereby invalidating standard errors and rendering the associated test statistics unreliable. Consequently, we employ the procedure initiated by Andersen and Bollerslev (1998) and recently applied by Andersen, Bollerslev, Diebold and Vega (2003).

Following Andersen, Bollerslev, Diebold and Vega (2003), we first obtain the residuals from a standard conditional mean model of the 5-minute exchange rate returns. We then use the concept of realized volatility and a Fourier flexible form to model the intraday pattern of these residuals. In the last step, we use the fitted residuals from the second model to perform a WLS estimation of the first model. We obtain consistent and asymptotically efficient estimates of the

\footnotetext{
${ }^{20}$ In general, intraday patterns arise in high-frequency data as the same events - lunch break, market opening, market closing and so forth - happen every day at the exact same time, creating correlations between certain 5-minute intervals now and certain 5-minute intervals several business days later. This periodicity is negligible for lower frequency data.
} 
response of the foreign exchange series to an intervention by this filtering procedure (see Andersen and Bollerslev, 1998, for details).

We model the response of the DKK/EUR exchange rate return, $R_{t}$, as a linear function of $\mathrm{J}$ lagged values of the return itself and the contemporaneous and $\mathrm{K}$ lags of the intervention variable, $\mathrm{I}_{\mathrm{t}}$ :

$$
R_{t}=\beta_{0}+\sum_{j=1}^{J} \beta_{j} R_{t-j}+\sum_{k=0}^{K} \gamma_{k} I_{t-k}+\varepsilon_{t}, t=1 . . T
$$

As noted earlier, $\mathrm{T}=80476$. We choose $\mathrm{J}=5$ based on the Schwartz and Akaike information criteria and we set $K=6$, i.e. we include 6 lags of the intervention variable (corresponding to 30 minutes) and vary this number in our robustness checks. We first estimate equation (1) by OLS and obtain the estimated residuals $\hat{\varepsilon}_{t} \cdot{ }^{21}$

The next step is to model the volatility pattern using the estimated residuals of equation (1). Again, we follow Andersen, Bollerslev, Diebold and Vega (2003) who suggest the following parameterization:

$$
\left|\hat{\varepsilon}_{t}\right|=c+\alpha \frac{\hat{\sigma}_{t}}{\sqrt{n}}+\sum_{k=0}^{K} \beta_{k} I_{t-k}+\left(\sum_{q=1}^{Q} \delta_{q} \cos \left(\frac{q 2 \pi t}{108}\right)+\varphi_{q} \sin \left(\frac{q 2 \pi t}{108}\right)\right)+\sum_{h=1}^{H} \eta_{h}\left(r_{t, h}^{E U R}-r_{t, h}^{D K K}\right)+u_{t}
$$

where $\hat{\varepsilon}_{t}$ is the residual of equation (1) and its absolute value proxies for the volatility in the 5minute interval $\mathrm{t}$, $\mathrm{c}$ is a vector of normalizing constants, $\mathrm{n}$ is the number of intervals on a day (in our case 108), $\hat{\sigma}_{t}$ is the one-day ahead volatility forecast for day t (i.e. the day that contains interval t), $\mathrm{q}$ is a specific intraday calendar effect, $\mathrm{Q}$ is the total number of calendar effects

\footnotetext{
${ }^{21}$ We follow Brandner, Grech and Stix (2006) and take into account the possibility of mean reversion by including, as an additional explanatory variable, a measure of the deviation of the DKK/EUR exchange rate from the central rate. The deviation variable proved insignificant in all our estimations and was therefore excluded from the remainder of the analysis. Considering that throughout the period under study the DKK/EUR exchange rate is comfortably in the interior of the $+/-2.25$ percent deviation band, it is not surprising that the impact of mean reversion is insignificant. Moreover, we included the DKK/EUR interest rate differential (contemporaneous and lagged values) to the returns model. We found these additional explanatory variables to be insignificant as well and, therefore, subsequently excluded these terms.
} 
accounted for $\left(\mathrm{Q}=8\right.$, based on the Schwartz and the Akaike information criteria), $\mathrm{r}^{\mathrm{EUR}}{ }_{-} \mathrm{r}^{\mathrm{DKK}}$ is the EUR-DKK interest rate differential, and $u_{t}$ denotes the residuals (assumed to be standard normal). ${ }^{22}$

We model the lower frequency intraday pattern (the first term after the vector of constants) using the concept of realized volatility (RV). RV is defined as the daily sum of squared returns. Andersen, Bollerslev and Diebold (2002) show that RV constitutes an unbiased, efficient and asymptotically consistent estimate of the true daily quadratic variation. A key advantage of using RV is that this semi-parametric approach does not require additional model estimation. ${ }^{23,24}$

Clearly, the realized volatility forecast cannot capture the observed cyclical intraday patterns. Therefore, in order to capture the slow decay in the autocorrelations (shown in Figure 2), we model the higher frequency periodicity by inclusion of a Fourier flexible form (see Gallant, 1981, Andersen and Bollerslev, 1998, and Andersen, Bollerslev, Diebold and Vega, 2003). Our goal is to fit the pattern of the residuals from equation (1) as best as possible and the Fourier flexible form allows for a model specification as flexible as possible. The Fourier flexible form consists of a number of sine- and cosine terms with varying degrees of periodicity (the terms in the parenthesis of equation 1).

Consistent with Andersen and Bollerslev (1998) and Andersen, Bollerslev, Diebold and Vega (2003) who include their macro news variables in the volatility equation, we include the intervention variable (i.e. our news variable) in the volatility model.

\footnotetext{
${ }^{22}$ As shown, we also include the differential between the DN policy rate (the Folio rate) and the ECB Refirate (contemporaneous as well as lagged values) to the volatility model. We set the number of lags to two, based on the Schwartz and the Akaike criteria. This inclusion improves the overall fit of the model. Importantly, whether or not we include the interest rate differential in our volatility model does not affect the significance of the coefficient estimates associated with the intervention variable.

${ }^{23}$ Andersen and Bollerslev (1998) suggest the use of a GARCH-type model for the lower frequency volatility using daily foreign exchange returns. While such models have been successful in modelling the variation of the daily financial market volatility (see Bollerslev, Chou and Kroner, 1992), we follow the more recent literature and use the concept of RV.

${ }^{24}$ While a seemingly obvious approach for calculating the RV is to use 5-minute returns, this would create an endogeneity problem as the 5-minute returns are also present in the estimated residuals from our initial estimation of equation 1. We, therefore, calculate the RV using 30 minute returns. See Anderson, Hansen and Sebestyén, 2006, for additional details.
} 
Our null hypothesis is that intervention is effective and works in the intended direction,

i.e. we expect a positive coefficient estimate for the interventions $\left(\gamma_{k}>0\right)$ such that a purchase of EUR against a sale of DKK is associated with a depreciation of the DKK vis-à-vis the EUR. ${ }^{25}$

\subsection{Structural breaks}

In order to ensure that our statistical inference is valid it is necessary to also test for structural breaks and parameter instability. ${ }^{26}$ We do so using the theory of Andrews (1993). Our null hypothesis is that the estimated parameters are stable across the sample, i.e. $H_{0}: \beta_{t}=\beta \forall t$ where $\beta$ is a vector of the coefficients of interest. This vector can be a subset of the parameters or the full parameter vector containing all the coefficients in the model. The alternative hypothesis is that parameter instability is present, i.e. $H_{1}: \beta_{t}=\left\{\begin{array}{c}\beta_{1} \text { for } t=1, . . T \pi \\ \beta_{2} \text { for } t=T \pi+1, . .\end{array}\right.$, where $\pi$ denotes the change point. The change point is a number strictly between 0 and 1, i.e. $\pi$ is a certain percentage of the full sample. ${ }^{27}$

Andrews (1993) suggests a test statistic of the form: $\sup _{(\pi \in \Pi)} X_{T}(\pi)$, where $X_{T}(\pi)$ can be the Wald, the Likelihood Ratio or the Lagrange Multiplier statistic. We apply the Wald test and use the following test statistic:

${ }^{25}$ We do not attempt to address an issue of simultaneity, if any. While the decision to intervene in the context of ERM II is necessarily determined by the exchange rate market developments, it seems in the context of our intraday analysis reasonable to assume that the intervention decision is not based on the contemporaneous exchange rate movement. See Neely (2005) for a general discussion and Neely (2006) for a survey-based assessment of how fast intervening central banks react to exchange rate market developments.

${ }^{26}$ Our data encompasses periods with varying degrees of daily volatility and periods with relatively strong DKK as well as relatively weak DKK against the EUR, as can be seen in Figure 1. Furthermore, the Danish monetary policy stance was held constant during the early part of our sample period while the latter part of our sample coincides with monetary policy easing. See Danmarks Nationalbank (2002, 2003b and 2004) for additional details regarding the Danish economy during the period under study.

${ }^{27}$ If the potential change point is known in advance, a simple Wald test (or similar) can be applied. However, we do not have advance knowledge regarding the exact timing of a potential change point, thereby invalidating a simple testing strategy. As shown in Andrews 1993, when the potential change point is unknown and treated as stochastic, complications arise as the change point parameter only appears under the alternative hypothesis. This invalidates the large sample asymptotic distributions for, as an example, the simple Wald test statistic. 
(3) $\sup _{(\pi \in \Pi)} W_{T}(\pi)=T\left(\hat{\beta}_{1}(\pi)-\hat{\beta}_{2}(\pi)\right)^{\prime}\left(\hat{V}_{1}(\pi) / \pi+\hat{V}_{2}(\pi) /(1-\pi)\right)^{-1}\left(\hat{\beta}_{1}(\pi)-\hat{\beta}_{2}(\pi)\right)$

where $\hat{\beta}_{i}(\pi), i=1,2$ are the partial-sample estimators of the coefficients of interest (using the first $\pi$ percent and the $1-\pi$ percent of the sample, respectively), and $\hat{V}_{i}(\pi), i=1,2$ are the estimated covariance matrices for the partial-samples. Andrews (1993) shows that this test statistic follows the square of a standardized tied-down Bessel process of order $p$, where $p$ is the number of restrictions in the hypothesis.

We first test for parameter stability across all the estimated coefficients and find the value of the test statistic $\sup _{(\pi \in \Pi)} W_{T}(\pi)$ to equal 165 at $\pi=0.2$ (i.e. for the sub-sample that includes the first 20 percent of the data). The critical value of a squared standardized tied-down Bessel process of order 13 is 31.10 , thus the null-hypothesis of parameter stability at the 20 percent change point mark is strongly rejected. We also utilize the ability of the testing procedure to focus on only a sub-sample of the parameter vector to test for parameter stability across the sum of the intervention coefficients and separately for each individual intervention coefficient. As an additional robustness check, we perform the same change point test for a specification with a full one-hour lag of interventions included (i.e. 12 lags of interventions). Again, we find significant evidence of a change point at the 20 percent mark.

In sum, we find strong and robust evidence of a change point at the 20 percent mark, implying a structural break on 16 August 2002. Accordingly, sub-sample 1 covers the 1 January 2002 to 16 August 2002 period, sub-sample 2 covers the 17 August 2002 to 31 December 2004 period. We carry out our estimations on the full sample as well as separately across the two subsamples. 


\section{5.}

\section{Results}

Table 3 displays the results of the WLS estimation of equation (1). The first column of estimated coefficients pertains to the full sample while the second and the third column show the results for sub-samples 1 and 2, respectively. As noted, intervention is considered effective if the associated coefficient estimate is positive (a positive amount of intervention constitutes a purchase of EUR against a sale of DKK; the exchange rate is measured in terms of DKK per EUR).

Table 3 shows that for the full sample the coefficient estimates associated with contemporaneous and the first lag of intervention are highly significant and negative, i.e. the opposite sign of what is expected, and lags 4 through 6 are significant and positive, i.e. in the intended direction. The Wald test of the hypothesis that the (positive) sum of the estimated intervention coefficients is equal to zero cannot be rejected.

Turning to sub-sample 1 , the next column shows that the first and the sixth lags of intervention are marginally significant and in opposite directions. Again, we cannot reject that the there is no cumulative effect of intervention. In sum, for the full sample and for sub-sample 1 we fail to detect a statistically significant cumulative effect of intervention.

The sub-sample 2 results, however, are different. The last column shows a negative and significant coefficient estimate of the first lag of intervention, and positive and significant coefficient estimates associated with the fourth and fifth lags. Comparing the magnitude (in absolute terms) of the two highly significant intervention coefficient estimates we see that the coefficient of the variable associated with the "correct" sign is almost twice the magnitude of the coefficient of the variable associated with the "wrong” sign. Moreover, the Wald test strongly rejects that the (positive) sum of the estimated intervention coefficients is equal to zero. Therefore, we accept the alternative hypothesis that the cumulative effect of intervention on the conditional mean of the exchange rate returns is positive. Put differently, the cumulative effect of intervention is statistically significant and intervention influences exchange rates as intended during the second period which accounts for 80 percent of our sample. 
While the primary purpose of our analysis is to assess the effect of intervention on the conditional mean of the exchange rate, our econometric methodology also provides some insights regarding the volatility effects of intervention. Table 4 displays the results of the volatility model described in equation (2). Only when estimating the volatility model across sub-sample 1 do we find significant effects of intervention (consistent with reduced volatility). Intervention has no significant volatility effects across either the full sample or sub-sample 2. Overall, these results do not suggest that intervention exerts a strong influence on exchange rate volatility.

Section 7 discusses why intervention is ineffective in sub-sample 1 but effective in subsample 2, the delayed effects of intervention, and the significant effects in the "wrong" direction.

\subsection{The Fit of the Model}

The validity of the WLS estimation procedure is contingent on the volatility model described by equation (2). This section assesses the fit of the model and the success of the WLS procedure.

As mentioned, Table 4 shows the results of the volatility model estimation. The Fstatistic (Wald test) associated with testing whether all of the estimated coefficients are jointly zero rejects this hypothesis for the full sample as well as for both sub-samples. However, the rejection level is substantially different across the full and the two sub-samples. The test statistic is only 7 for sub-sample 1 but higher than 300 for the full sample and for sub-sample 2 . Furthermore, nearly all the trigonometric terms are insignificant for sub-sample 1 while nearly all the trigonometric terms are significant for the full sample and for sub-sample 2. This indicates that our volatility model captures the intraday periodicity for sub-sample 2 but less so for subsample 1, i.e. the fit of the volatility model is better for sub-sample $2 .^{28}$

\footnotetext{
${ }^{28}$ Importantly, our HAC robustness tests (discussed in the next section) also reject that intervention is effective during sub-sample 1, implying that the less than perfect fit of the WLS estimation across subsample 1 is not the reason why we fail to find significant effects of intervention during the first 20 percent our data.
} 
As another measure of fit we once again follow Andersen, Bollerslev, Diebold and Vega (2003) and display in Figures 3a (sub-sample 1) and 3b (sub-sample 2) plots of the absolute average residuals (for each 5 minute interval across all the included 752 trading days) estimated from the initial OLS regression of equation (1) juxtaposed against the fitted absolute average residuals from the estimation of equation (2). As the plot shows, our volatility model provides a good fit for both sub-samples. ${ }^{29}$

Figure 4 provides another measure of the overall success of our econometric procedure. The dark observations are the raw foreign exchange rate returns while the light observations are our fitted foreign exchange rate returns. The figure at the top plots the fitted returns from our initial OLS estimation of equation (1) against the raw returns. The OLS procedure clearly fails to capture the pattern of the raw returns. The figure at the bottom plots the fitted returns from our WLS estimation of equation (1) against the raw returns. Comparison of the two figures further confirms the success of the WLS procedure.

\section{Robustness}

In order to test the robustness of our results, we carry out the analysis using a different econometric procedure, a different intervention lag-structure, and different RV measures. Additionally, we control for the timed announcement of other Danish and EUR macro news.

First, the gain in efficiency from the WLS procedure is potentially costly in terms of inconsistent estimates if the residuals from the initial estimation of equation (1) are improperly fitted in the volatility model described by equation (2). In order to address this potential concern we momentarily disregard the two-step WLS procedure and, instead, estimate the effects of

\footnotetext{
${ }^{29}$ We use relatively many (8) sine and cosine terms compared to other applications of the methodology (see, for example, Andersen, Bollerslev, Diebold and Vega, 2003, Andersson, Hansen, and Sebestyén, 2006, and Beattie and Fillion, 1999, who typically use only 4 or 5). This is, however, not surprising. The previously discussed properties of the Danish currency market forced us to model a relatively short interval of the business day where the intra-day periodicity is jagged. We therefore need several terms to fit the many jags.
} 
intervention on exchange rate returns using heteroskedasticity- and serial-correlation consistent (HAC) standard errors (i.e. we re-estimate equation (1) using HAC errors). The HAC results displayed in Table 5 are qualitatively identical to the conditional mean results based on the more sophisticated two-step WLS procedure. ${ }^{30}$

Second, in order to test for delayed effects of intervention beyond the 6th lag captured by our baseline model, we re-estimate our models with 12 lags of intervention included. We do so using both the WLS and the HAC procedure. Table 6 displays the results based on the HAC procedure. While the 7th and the 10th lags are marginally significant in sub-sample 1 and the 7th lag is significant in sub-sample 2, our previously discussed results regarding cumulative effects remain. Furthermore, when using instead the WLS procedure (not shown for brevity), the two marginally significant effects in sub-sample 2 become insignificant, confirming that it takes about 30 minutes before the exchange rate has fully adjusted to an intervention operation.

Third, while our baseline model uses a RV measure based on 30 minute frequency returns (pertaining to equation 2), we also estimate the model using RV measures based on 10 and 60 minute frequency returns. Our results (not shown for brevity) are robust across each of these RV measures. ${ }^{31}$

Fourth, we know from Almeida, Goodhart, and Payne (1998) and Andersen, Bollerslev, Diebold and Vega (2003) and others that exchange rates respond to (non-intervention) macro news. In order to ensure that our estimated effects of intervention are not tainted by the coincidental arrival of other macro news we extend our analysis to include several types of both Danish and EUR macro news. Specifically, we include additional explanatory variables capturing

\footnotetext{
${ }^{30}$ As previously mentioned, Andersen, Bollerslev, Diebold and Vega (2003) also use HAC estimations to test the robustness of their WLS generated results. They offer a detailed discussion of why the WLS procedure is the more appealing of the two.

${ }^{31}$ Moreover, we find that the baseline 30 minute RV measure fits the data the best (as measured by tratios). Our findings are, furthermore, robust to replacing the RV series with the daily volatility series derived from a standard GARCH(1,1) model (as originally proposed by Andersen and Bollerslev 1998). In terms of t-ratios, the model using daily volatilities derived from the GARCH(1,1) estimation is outperformed by any of the RV-based models, regardless of the specific RV measure.
} 
timed news releases by Statistics Denmark regarding balance of payments, CPI, EU harmonized CPI, real activity, unemployment, and consumer expectations. In the same fashion we also control for timed macro announcements from the ECB. As expected, several of these news variables are significant. Most important to our investigation, our results regarding the effects of intervention are completely unaffected by the inclusion of these control variables. ${ }^{32}$

\section{Discussion}

We are unable to detect a significant cumulative effect of intervention for sub-sample 1 while we find robust significant evidence of effectiveness when analyzing sub-sample 2, the latter 80 percent of our sample. Before we discuss why intervention is ineffective in sub-sample 1 but effective in sub-sample 2, it is useful to assess the economic significance of our results.

In the case of sub-sample 1 , the cumulative effect of intervention is statistically insignificant and, therefore, the economic impact is nil. The statistically significant coefficient estimate associated with the cumulative effect of intervention across sub-sample 2 is $0.3 e(-6)$, or 0.0000006, and pertains to an intervention operation of EUR 1 million. This implies that a EUR 100 million intervention is, on average, associated with a $0.003 \%$ change in the level of the DKK/EUR exchange rate. This suggests that, regardless of the statistically significance, the economic importance of intervention is negligible. ${ }^{33}$

However, a closer look at the intervention variable in conjunction with the economic fundamentals reveals that this is not the whole story. As Sarno and Taylor (2001, p. 850) note, “[Intervention] policies which are inconsistent with the underlying stance of monetary and fiscal policy are doomed to ultimate failure”. With respect to fundamentals and, in particular, the

\footnotetext{
32 The overview of timed news releases from Statistics Denmark and the ECB, and the associated robustness results, are not shown for brevity but available from the authors upon request.

${ }^{33}$ By contrast, Dominguez and Frankel (1993) estimate the economic effect of an unannounced USD 100 million Bundesbank intervention to move the DEM/USD exchange rate by $0.081 \%$ and Kearns and Rigobon (2005) estimate the effect of a USD 100 million intervention to move the exchange rate by $1.8 \%$ in the case of the AUD/USD rate and $0.2 \%$ in the case of the JPY/USD. Both studies examine daily data.
} 
monetary policy stance, our two sample periods are distinctly different. Throughout sub-sample 1 the Danish policy rate was held constant at $3.25 \%$, i.e. the monetary policy stance was unchanged. During sub-sample 2, however, monetary policy was easing as the policy rate was gradually changed from $3.25 \%$ to $2 \%$ (see Danmarks Nationalbank 2002, 2003b and 2004). ${ }^{34}$ Therefore, interventions during sub-sample 1 (all purchases of EUR) were neither consistent nor inconsistent with the Danish fundamentals while intervention purchases of EUR during subsample 2 were consistent with fundamentals but intervention sales were inconsistent. To pursue this further, we re-estimate the effects of intervention across sub-sample 2 (using the WLS procedure) with intervention sales and purchases entering as separate explanatory variables. ${ }^{35} \mathrm{We}$ find that intervention sales (inconsistent with monetary policy easing) are statistically insignificant and we find that intervention purchases (consistent with monetary policy easing) are significant. Moreover, the coefficient estimate associated with the cumulative effect of intervention purchases is $0.3 e(-4)$, implying that the economic impact of "consistent intervention" is such that a EUR 100 million intervention is, on average, associated with a $0.3 \%$ change in the exchange rate. In other words, the economic impact of consistent intervention is substantial.

Microstructure models of intervention suggest that the effects of intervention depend on the state of the foreign exchange market. ${ }^{36}$ Furthermore, microstructure theory suggests that periods of high volatility correspond to a high concentration of informed trading. ${ }^{37}$ Dominguez (2003) examines whether intervention is more effective during a high degree of informed trading and finds that the intraday price effect of Fed intervention in the DEM/USD market is 28 percent higher when the degree of informed trading is high. ${ }^{38}$ Our two sub-samples are associated with very different degrees of DKK/EUR exchange rate volatility. Figure 1 shows that the exchange

\footnotetext{
${ }^{34}$ The ECB monetary policy stance was also unchanged during Sample 1 and eased during Sample 2. The monetary policy easing of the ECB during Sample 2 occurred at a slower pace compared to the Danish monetary policy easing.

${ }^{35}$ These results are not shown for brevity but available from the authors upon request.

${ }^{36}$ See Pasquariello (2006b) and Vitale (2006).

${ }^{37}$ See the information microstructure model of Admati and Pfleiderer (1988).

${ }^{38}$ Dominguez (2003) uses trading volume as a measure of the degree of informed trading.
} 
rate swings during the first sub-sample are noticeably smaller than during the second sub-sample. To quantify the difference in volatility across the two sub-samples we calculate the daily RV (using 5-minute exchange rate returns). Figure 5 displays the plot of the RV across the full sample period. The figure shows a relatively calm first sub-sample against a much more volatile second sub-sample. In fact, the average RV across sub-sample 1 is 70 percent lower than the average RV across the latter sub-sample. Put differently, we find that intervention is effective during the high volatility period while we find no significant cumulative effects of intervention during the low volatility period. This is consistent with the findings of Dominguez (2003). ${ }^{39}$

Table 7 presents an overview of exchange rate volatility, direction of monetary policy (fundamentals) and results (statistically as well as economically) across the two sub-samples.

Turning to the speed of the adjustment process, it seems surprising that it takes about 30 minutes before the exchange rate has fully absorbed the intervention news. At a first glance, this finding seems to counter the conclusions of the intraday studies by Almeida, Goodhart, and Payne (1998) and Andersen, Bollerslev, Diebold and Vega (2003) who show that the conditional mean of the exchange rate generally adjusts immediately (i.e. jumps) in response to macro news. However, the findings of their studies pertain to macro news where the announcement time is known in advance. This is clearly not the case in our context of intervention news. DN interventions are unannounced and carried out on a discretionary basis and, therefore, the foreign exchange market participants cannot know in advance whether an intervention will occur and if so at what time. In other words, the aforementioned studies investigate how exchange rates respond to scheduled news whereas we investigate how exchange rates respond to non-scheduled news. Our findings suggest that the adjustment process in case of the latter is not instantaneous.

\footnotetext{
${ }^{39}$ In a recent study of daily effects of Japanese foreign exchange intervention, Fatum and Hutchison (2006) also find evidence of differing effects of intervention across (three) distinct sub-samples. They suggest that an inverse relationship between intervention frequency and effectiveness is the explanation. In our context, however, we can disregard this frequency explanation since the frequency of DN intervention is virtually the same in both our sub-samples.
} 
Moreover, recent theoretical work on microstructure models of intervention shows that the specific way in which interventions are carried out matter for their effectiveness. ${ }^{40}$ We suspect that the way the DN intervention transactions are carried out may offer an important element towards explaining why we observe a gradual adjustment process as well as initial effects in the opposite direction of what is intended. During the period under study about half of the intervention transactions are carried out by phone, i.e. directly between the DN dealer in charge of the intervention operation and the commercial bank counterpart. ${ }^{41}$ Intervention by phone implies that the instant the intervention operation is conducted and for a short duration thereafter, only this particular counterpart is aware of the intervention news while the rest of the market is momentarily unaware. Put differently, while the intervention transaction time-stamp provides the exact time of the transaction between DN and the particular market counterpart, the specific way in which the transaction is carried out determines whether this is also the exact time that the general market becomes aware of the intervention news. As a result of intervening by phone, it may take longer before the general market has fully absorbed these intervention operations.

Another seemingly surprising finding is the significant effects in the "wrong” direction of the contemporaneous and the first lag of intervention. Our conjecture is that the fact that intervention is unannounced and, furthermore, in some cases carried out by phone, can offer one possible explanation. The DN intervention policy is characterized as leaning-against-the-wind, i.e. the DN intervenes against the prevailing exchange rate trend (for example, the DN sells DKK and buys EUR in response to a DKK appreciation vis-à-vis the EUR). If the general market is initially unaware of the intervention operation and, therefore, has not yet absorbed and adjusted to the intervention news, then the exchange rate at the instant the intervention occurs and for a brief period thereafter is not responding to the intervention but, instead, it continues the trend that

\footnotetext{
${ }^{40}$ See Vitale (2006).

${ }^{41}$ Since early 2005 (i.e. after our sample period ended) all DN interventions have been carried out using a centralized market place. We do not currently have access to DN intervention data encompassing only intervention transactions by centralized trading. Investigating the importance of switching from phone and centralized trading to only centralized trading is, therefore, left for future research.
} 
brought about the leaning-against-the-wind intervention operation. In that case, the significant effects in the "wrong" direction do not constitute a perverse response to intervention but, instead, the continuation of the exchange rate movement that made the DN deem the intervention operation necessary in the first place. ${ }^{42}$

\section{Conclusion}

This paper investigates the real-time (intraday) effects of Danish intervention in the EUR market over the 1 January 2002 to 31 December 2004 period, using proprietary intraday intervention data provided by the Danish central bank. Denmark is currently pursuing an active intervention policy under the provisions of ERM II. Prior participation in ERM II is a requirement for adoption of the EUR, thus the Danish exchange rate management experience seems particularly relevant for not only Denmark but also for the 6 new European Union (EU) member states that are also currently participating in ERM II.

We use the WLS time-series econometrics of Andersen and Bollerslev (1998) and Andersen, Bollerslev, Diebold and Vega (2003). In addition, we follow Andrews (2003) and detect a structural break in our data and, consequently, we carry out our investigation on our full sample as well as separately across two sub-samples. We perform several robustness tests. We replace the two-step WLS estimation procedure with the one-step HAC estimation, extend the number of lags of intervention included in our models, use different RV measures, and control for other timed Danish and EUR macroeconomic news. The robustness tests confirm the results of our baseline analysis.

\footnotetext{
${ }^{42}$ Figure 6 shows the average unconditional change in the 5-minute exchange rate return across the 60 minutes preceding interventions (returns are normalized to allow for an aggregation of both purchases and sales of DKK). Supporting our conjecture, the figure shows the downward sloping trend in the exchange rate return that, if intervention is initially unnoticed by the broader market and the trend continues, would be consistent with exchange rate movements in the "wrong" direction coinciding with the contemporaneous and the first lag of intervention. Figure 6 also confirms that the interventions under study are consistent with a leaning-against-the-wind policy and that intervention does not appear to be responding to the contemporaneous exchange rate movement. The latter implies that our results are free of simultaneity bias.
} 
We find evidence that intervention affects the level of the exchange rate in the intended direction. This is in line with the results of the intraday studies by Fatum and King (2005), Fischer and Zurlinden (1999), Pasquariello (2006a), Payne and Vitale (2003) and others. This result pertains to 80 percent of our sample period (sub-sample 2). We find no significant cumulative effects of intervention when analyzing the full sample and separately the first 20 percent of our sample period (sub-sample 1).

During the first part of our sample, the Danish monetary policy stance was held constant and, therefore, intervention during sub-sample 1 was neither consistent nor inconsistent with monetary policy fundamentals. During the second part of our sample, however, monetary policy was easing. Accordingly, intervention sales of EUR were inconsistent with fundamentals while intervention purchases of EUR were consistent. When we re-estimate the effects of intervention across sub-sample 2 with intervention sales and purchases entering as separate explanatory variables, we find that intervention sales are statistically insignificant while intervention purchases are significant. The coefficient estimate associated with the cumulative effect of intervention purchases during sub-sample 2 implies that a EUR 100 million intervention is, on average, associated with a $0.3 \%$ change in the exchange rate. This result suggests that fundamentals matter for the effectiveness of intervention and shows that the economic impact of “consistent intervention” is substantial.

Microstructure models of intervention predict that the effects of intervention depend on the state of the exchange rate market. We observe a marked difference in exchange rate volatility across our two sub-samples, with an average RV across sub-sample 1 that is 70 percent lower than the average RV across sub-sample 2. Taken together with our results, therefore, this suggests that intervention is effective when the exchange rate market is volatile, consistent with a high concentration of informed trading, and ineffective when it is calm, consistent with a low degree of informed trading. This is in line with Dominguez (2003), who finds that the intraday effects of Fed intervention are stronger when the degree of informed trading is high. 
We also find that it takes at least 30 minutes before the exchange rate has fully adjusted to the intervention news. This is not surprising when we consider that Danish interventions are unannounced and carried out on a discretionary basis and, therefore, the exchange rate market does not know in advance whether an intervention will occur and if so at what time. Furthermore, institutional details regarding the specific way in which a large part of the Danish intervention transactions in our sample is carried out - by phone as opposed to via centralized electronic trading - further help explain the observed delayed exchange rate response.

In conclusion, our study supports the following normative recommendations for intervention policy:

- Intervention is an important short-term policy instrument for exchange rate management

- $\quad$ The effectiveness of intervention depends on whether intervention is consistent with monetary policy fundamentals

- $\quad$ The economic effect of an intervention that is consistent with fundamentals and carried out during a period of relatively high exchange rate volatility is substantial while the economic effect of an intervention in the opposite direction of fundamentals is negligible

- The exchange rate does not adjust instantaneously to discretionary and unannounced interventions and, therefore, it is necessary to allow for an adjustment period of at least 30 minutes before assessing the full effect of an intervention operation. 


\section{References}

Admati, Anat R., and Paul Pfleiderer (1988): “A Theory of Intraday Patterns: Volume and Price Variability”, Review of Financial Studies 1, 3-40.

Almeida, Alvaro, Charles Goodhart and Richard Payne (1998): "The Effects of Macroeconomic News on High Frequency Exchange Rate Behavior", Journal of Financial and Quantitative Analysis 33, 383-408.

Andersen, Torben G. and Tim Bollerslev (1998): "Deutsche Mark-Dollar Volatility: Intraday Activity Patterns, Macroeconomic Announcements, and Longer-Run Dependencies”, Journal of Finance 53, 219-265.

Andersen, Torben G., Tim Bollerslev, and Francis X. Diebold (2002): Handbook of Financial Econometrics, Edited by Yacine Ait-Sahalia and Lars Peter Hansen.

Andersen, Torben G., Tim Bollerslev, Francis X. Diebold, and Clara Vega (2003): "Micro Effects of Macro Announcements: Real-Time Price Discovery in Foreign Exchange”, American Economic Review 93, 38-62.

Andersson, Magnus, Lars Jul Hansen, and Szabolcs Sebestyén (2006): "Which News Moves the Euro Area Bond Market?”, ECB Working Paper No. 631.

Andrews, D. W. K. (1993): “Tests for Parameter Instability and Structural Change with Unknown Change Point,” Econometrica 61, 821-856.

Beattie, Neil and Jean-Francois Fillion (1999): “An Intraday Analysis of the Effectiveness of Foreign Exchange Intervention”, Bank of Canada Working Paper 99-4.

Beine, Michel, Jérôme Lahaye, Sébastien Laurent, Christoffer J. Neely, and Franz C. Palm (2006): "Central Bank Intervention and Exchange Rate Volatility, Its Continuous and Jump Components”, Federal Reserve Bank of St. Louis Working Paper No. 06-031B, and forthcoming in the International Journal of Finance and Economics.

Beine, Michel, Sébastien Laurent and Franz C. Palm (2003): “Central Bank Forex Interventions Assessed Using Realized Moments”, University of Brussels mimeo.

BIS (2005): "Foreign Exchange Market Intervention in Emerging Markets: Motives, Techniques and Implications”, BIS Paper No. 24.

Bollerslev, Tim, Ray Y. Chou and Kenneth F. Kroner (1992): "ARCH Modelling in Finance: A Selective Review of the Theory and Empirical Evidence”, Journal of Econometrics 52, 5-59.

Bollerslev, Tim and Ian Domowitz (1993): "Trading Patterns and Prices in the Interbank Foreign Exchange Market”, Journal of Finance 48, 1421-1443.

Brandner, Peter, Harald Grech and Helmut Stix (2006): “The Effectiveness of Central Bank Intervention in the EMS: The post 1993 Experience”, Journal of International Money and Finance 25, 580-597. 
Burkhard, Lukas and Andreas M. Fischer (2006): "Communicating Intervention Threats at the Zero Bound”, Swiss National Bank mimeo.

Cai, Jun; Yan-Leung Cheung; Raymond S.K. Lee and Michael Melvin (2001): “Once-In-AGeneration' Yen Volatility in 1998: Fundamentals, Intervention, and Order Flow”, Journal of International Money and Finance 20, 327-347.

Campbell, J. Y., A.W. Lo and A. C. MacKinlay (1997): "The Econometrics of Financial Markets”, Princeton University Press.

Chang Yuanchen, and Stephen J. Taylor (1998): "Intraday Effects of Foreign Exchange Intervention by the Bank of Japan”, Journal of International Money and Finance 17, 191-210.

Chari, Anusha (2006): "Heterogeneous Market-Making in Foreign Exchange Markets: Evidence from Individual Bank Responses to Central Bank Intervention”, forthcoming in the Journal of Money, Credit and Banking.

Dacorogna, Michel M., Ulrich A. Müller, Robert J. Nagler, Richard B. Olsen and Olivier V. Pictet (1993): “A Geographical Model for the Daily and Weekly Seasonal Volatility in the Foreign Exchange Market”, Journal of International Money and Finance 12, 413-438.

Danielsson, Jon and Richard Payne (1999): "Real Trading Patterns and Prices in Spot Foreign Exchange Markets”, London School of Economics mimeo.

Danmarks Nationalbank (2002): “Nationalbankens Beretning og Regnskab”, Danmarks Nationalbank, Copenhagen.

Danmarks Nationalbank (2003a): “Monetary Policy of Denmark”, second edition, Danmarks Nationalbank, Copenhagen.

Danmarks Nationalbank (2003b): “Nationalbankens Beretning og Regnskab”, Danmarks Nationalbank, Copenhagen.

Danmarks Nationalbank (2004): “Nationalbankens Beretning og Regnskab”, Danmarks Nationalbank, Copenhagen.

Disyatat, P. and Gabriele Galati (2005): “The Effectiveness of Foreign Exchange Intervention in Emerging Market Countries: Evidence from the Czech Koruna”, forthcoming in the Journal of International Money and Finance.

Dominguez, Kathryn M. (2003): “The Market Microstructure of Central Bank Intervention”, Journal of International Economics 59, 25-45.

Dominguez, Kathryn M. (2006): "When Do Central Bank Interventions Influence Intra-Daily and Longer-Term Exchange Rate Movements?”, Journal of International Money and Finance 25, 1051-1071.

Dominguez, Kathryn M.E. and Jeffrey A. Frankel (1993): Does Foreign Exchange Intervention Work? Institute for International Economics (Washington, D.C.). 
D’Souza, Chris (2002): “A Market Microstructure Analysis of Foreign Exchange Intervention in Canada”, Bank of Canada Working Paper 2002-16.

European Central Bank (2004): "The monetary policy of the ECB”, European Central Bank, Frankfurt.

European Union (2006): “European Central Bank Agreement of 16 March 2006”, Official Journal of the European Union 2006/C 73/08.

Fatum, Rasmus (2006): "Daily Effects of Foreign Exchange Intervention: Evidence from Official Bank of Canada Data”, forthcoming in the Journal of International Money and Finance.

Fatum, Rasmus and Michael M. Hutchison (2006): "Evaluating Foreign Exchange Market Intervention: Self-selection, Counterfactuals and Average Treatment Effects”, SCCIE Working Paper No. 06-04.

Fatum, Rasmus and Michael King (2005): "Rules versus Discretion: Evidence from Intraday Foreign Exchange Intervention Data”, SCCIE Working Paper No. 04-24.

Fischer, Andreas M. (2003): "Measurement Error and the Profitability of Interventions: A Closer Look at SNB Transactions Data”, Economic Letters 81, 137-142.

Fischer, Andreas M. (2004): “The Inaccuracy of Reuters Reports for Swiss Interventions”, CEPR Discussion Paper No. 4359 and forthcoming in the Journal of International Money and Finance.

Fischer, Andreas M. and Mathias Zurlinden (1999): "Exchange Rate Effects of Central Bank Interventions: An Analysis of Transaction Prices”, Economic Journal 109, 662-676.

Gallant, A. Ronald (1981): “On the Bias in Flexible Functional Forms and Essentially Unbiased Form: The Fourier Flexible Form”, Journal of Econometrics 15, 211-245.

Goodhart, Charles A.E. and Thomas Hesse (1993): "Central Bank Forex Intervention Assessed in Continuous Time”, Journal of International Money and Finance 12, 368-389.

Goodhart, Charles, Takatoshi Ito and Richard Payne (1996): “One Day in June 1993: A Study of the Working of the Reuters 2000-2 Electronic Foreign Exchange Trading System” in Jeffrey A. Frankel, Giampaolo Galli and Alberto Giovannini, eds., The Microstructure of Foreign Exchange Markets, 107-179. University of Chicago Press, Chicago.

Hochreiter, Eduard and Pierre Siklos (2006): "Introductory Remarks for the Contemporary Economic Policy Special Section on Monetary Policy Issues of New EU-Member and Candidate Countries”, Contemporary Economic Policy 24, p. 473-474.

Humpage, Owen (2003): “Government Intervention in the Foreign Exchange Market”, Federal Reserve Bank of Cleveland Working Paper No. 03-15.

Kearns and Rigobon (2005): "Identifying the Efficacy of Central Bank Interventions: Evidence from Australia and Japan”, Journal of International Economics 66, 31-48. 
Kim, Suk-Joong (2005): "Intraday Evidence of Efficacy of 1991-2004 Yen Intervention by the Bank of Japan”, forthcoming in the Journal of International Financial Markets, Institutions and Money.

Neely, Christopher J. (2005): “An Analysis of Recent Studies of the Effect of Foreign Exchange Intervention”, Federal Reserve Bank of St. Louis Working Paper No. 05-30.

Neely, Christopher J. (2006): “Authorities’ Beliefs about Foreign Exchange Intervention and Their Correlates: Getting Back under the Hood”, Federal Reserve Bank of St. Louis mimeo.

Pasquariello, Paolo (2006a): "Informative Trading or Just Costly Noise? An Analysis of Central Bank Interventions”, forthcoming in the Journal of Financial Markets.

Pasquariello, Paolo (2006b): "Central Bank Intervention and the Intraday Process of Price Formation in the Currency Markets”, University of Michigan mimeo.

Payne, Richard and Paolo Vitale (2003): “A Transaction Level Study of the Effects of Central Bank Intervention of Exchange Rates”, Journal of International Economics 61, 331-352.

Peiers, Bettina (1997): "Informed Traders, Intervention and Price Leadership: A Deeper View of the Microstructure of the Foreign Exchange Market”, Journal of Finance 52, 1589-1614.

Sarno, Lucio and Mark P. Taylor (2001): “Official Intervention in the Foreign Exchange Markets: Is It Effective and, If So, How Does It Work?”, Journal of Economic Literature 34, 839-868.

Scalia, Antonio (2004): "Is Foreign Exchange Intervention Effective? Some Micro-Analytical Evidence from Central Europe”, Banca d’Italia mimeo.

Vitale, Paolo (2006): “A Market Microstructure Analysis of Foreign Exchange Intervention”, ECB Working Paper No. 629. 
TABLE 1: Summary Statistics for the Intervention Variable Number of Interventions Average amount (mill. EUR)

Daily interventions

\begin{tabular}{|l|cc|}
\hline All & 89 & 164 \\
Purchases & 68 & 158 \\
Sales & 21 & -182 \\
\hline \multicolumn{2}{|l|}{ Intraday interventions } \\
\hline All & 220 & 67 \\
Purchases & 157 & 69 \\
Sales & 63 & 61 \\
\hline
\end{tabular}


TABLE 2: Summary Statistics for 5 Minute DKK/EUR Exchange Rate Returns

\begin{tabular}{|c|c|c|c|}
\hline Mean & Std. Dev. & Skewness & Kurtosis \\
\hline $\begin{array}{c}0 \\
(\sim 0)\end{array}$ & $\begin{array}{c}0.00013 \\
(-)\end{array}$ & $\begin{array}{c}0.0146 \\
(0.0086)\end{array}$ & $\begin{array}{c}18^{* *} \\
(0.0173)\end{array}$ \\
\hline Minimum & Maximum & $\begin{array}{l}\text { BJ-test for } \\
\text { normality }\end{array}$ & LB Q-test (5-day lag) \\
\hline-0.1724 & 0.2215 & $\begin{array}{c}754720 \\
{[5.99]}\end{array}$ & $\begin{array}{l}16068 \\
{[595]}\end{array}$ \\
\hline
\end{tabular}

NOTES:

Data runs from January 1, 2002 to December 31, 2004.

The data consists of 80476 observations on DKK/EUR exchange rate

The returns are calculated from bid- and ask prices from Olsen Financial

Technologies.

* Denotes significance at 90\%, ** Denotes significance at 95\%, *** Denotes significance at $99 \%$

Standard Errors in ( ) below the point estimates; critical values in [ ]. 


\begin{tabular}{|c|c|c|c|}
\hline \multicolumn{4}{|c|}{ TABLE 3: WLS Estimation of Equation (1): Mean Equation } \\
\hline & Full Sample & Sub-sample I & Sub-sample II \\
\hline \multicolumn{4}{|l|}{ Constant (e-6) } \\
\hline$\beta(0)$ & $\begin{array}{c}0.004 \\
(0.0333)\end{array}$ & $\begin{array}{c}-0.15 \\
(0.7142)\end{array}$ & $\begin{array}{c}0.06 \\
(0.2857)\end{array}$ \\
\hline \multicolumn{4}{|l|}{ Lags of FX-returns } \\
\hline $\begin{array}{l}\beta(1) \\
\beta(2) \\
\beta(3) \\
\beta(4) \\
\beta(5)\end{array}$ & $\begin{array}{c}-0.64 * * * \\
(0.0067) \\
-0.45^{* * *} \\
(0.0075) \\
-0.31^{* * *} \\
(0.0070) \\
-0.20^{* * *} \\
(0.0063) \\
-0.10^{* * *} \\
(0.0050)\end{array}$ & $\begin{array}{c}-0.76^{* * *} \\
(0.0097) \\
-0.58^{* * *} \\
(0.0116) \\
-0.42^{* * *} \\
(0.0119) \\
-0.26^{* * *} \\
(0.0107) \\
-0.13^{* * *} \\
(0.0082)\end{array}$ & $\begin{array}{c}-0.61^{* * *} \\
(0.0078) \\
-0.43^{* * *} \\
(0.0086) \\
-0.29^{* * *} \\
(0.0079) \\
-0.19^{* * *} \\
(0.0072) \\
-0.10^{* * *} \\
(0.0061)\end{array}$ \\
\hline \multicolumn{4}{|l|}{ Interventions (e-6) } \\
\hline $\begin{array}{l}\gamma(0) \\
\gamma(1) \\
\gamma(2) \\
\gamma(3) \\
\gamma(4) \\
\gamma(5) \\
\gamma(6)\end{array}$ & $\begin{array}{c}-0.15^{* * *} \\
(0.0560) \\
-0.16^{* * *} \\
(0.0578) \\
0.06 \\
(0.0632) \\
-0.05 \\
(0.0714) \\
0.13^{* *} \\
(0.0578) \\
0.12^{* *} \\
(0.0533) \\
0.15^{* * *} \\
(0.0641) \\
\end{array}$ & $\begin{array}{c}-0.32 \\
(0.4638) \\
-0.26^{*} \\
(0.1844) \\
0.06 \\
(0.1579) \\
-0.03 \\
(0.1250) \\
0.12 \\
(0.1091) \\
-0.13 \\
(0.1429) \\
0.16^{*} \\
(0.1185) \\
\end{array}$ & $\begin{array}{c}-0.08 \\
(0.0696) \\
-0.17 * * * \\
(0.0369) \\
0.04 \\
(0.0702) \\
-0.06 \\
(0.0857) \\
0.10^{*} \\
(0.0676) \\
0.36^{* * *} \\
(0.0679) \\
0.11 \\
(0.0859) \\
\end{array}$ \\
\hline $\begin{array}{l}30 \text { min sum (e-6) } \\
\text { intervention } \\
\text { coefficient. (Robust } \\
\text { Wald statistic) }\end{array}$ & $\begin{array}{c}0.1 \\
{[1.91]}\end{array}$ & $\begin{array}{c}-0.39 \\
{[0.63]}\end{array}$ & $\begin{array}{c}0.31^{* * * *} \\
{[7.28]}\end{array}$ \\
\hline \#Interventions & 220 & 58 & 162 \\
\hline \multicolumn{4}{|c|}{$\begin{array}{l}\text { NOTES: } \\
\text { (a) }{ }^{*} \text { Denotes significance at } 90 \%,{ }^{* *} \text { Denotes significance at } 95 \%, * * * \text { Denotes } \\
\text { significance at } 99 \% \\
\text { (b) Standard Errors in ( ) below the point estimates; test statistic values in [ ]; lags in ( ) } \\
\text { in Variable Names } \\
\text { (c) The dependent variable is the first difference of the log of the daily DKK/EUR mid- } \\
\text { point exchange rate. } \\
\text { (d) The independent variables are current and lags of intervention and lags of the } \\
\text { dependent variable. }\end{array}$} \\
\hline
\end{tabular}




\begin{tabular}{|c|c|c|c|}
\hline \multicolumn{4}{|c|}{ TABLE 4: Estimation of Equation (2): Volatility Equation } \\
\hline & Full-sample & Sub-sample I & Sub-sample II \\
\hline \multicolumn{4}{|l|}{ Constants } \\
\hline Constant & $\begin{array}{c}0.0025 * * * \\
(0.0004)\end{array}$ & $\begin{array}{l}-0.0004 \\
(0.0007)\end{array}$ & $\begin{array}{r}0.003 * * * \\
(0.0005)\end{array}$ \\
\hline Normalising constant I & $\begin{array}{c}-0.0019 * * * \\
(0.0003)\end{array}$ & $\begin{array}{c}0.0003 \\
(0.0005)\end{array}$ & $\begin{array}{c}-0.003^{* * *} \\
(0.0005)\end{array}$ \\
\hline Normalising constant II & $\begin{array}{c}0.0002 * * * \\
(0.00004)\end{array}$ & $\begin{array}{l}-0.0004 \\
(0.0006)\end{array}$ & $\begin{array}{r}0.0003^{* * *} \\
(0.00005)\end{array}$ \\
\hline \multicolumn{4}{|l|}{ Interday-volatility } \\
\hline Realised-vol/GARCH & $\begin{array}{c}0.27 * * * \\
(0.005)\end{array}$ & $\begin{array}{r}0.13^{* * *} \\
(0.016)\end{array}$ & $\begin{array}{l}0.27^{* * *} \\
(0.005)\end{array}$ \\
\hline \multicolumn{4}{|l|}{ Sine-terms (e-3) } \\
\hline$\delta(1)$ & $\begin{array}{c}-0.103^{* * *} \\
(0.017)\end{array}$ & $\begin{array}{c}0.021 \\
(0.028)\end{array}$ & $\begin{array}{c}-0.14 * * * \\
(0.02)\end{array}$ \\
\hline$\delta(2)$ & $\begin{array}{l}-0.01 * * * \\
(0.0017)\end{array}$ & $\begin{array}{c}0.001 \\
(0.003)\end{array}$ & $\begin{array}{c}-0.012 * * * \\
(0.002)\end{array}$ \\
\hline$\delta(3)$ & $\begin{array}{c}0.006 * * * \\
(0.0014)\end{array}$ & $\begin{array}{l}-0.003^{*} \\
(0.002)\end{array}$ & $\begin{array}{r}0.008 * * * \\
(0.0015)\end{array}$ \\
\hline$\delta(4)$ & $\begin{array}{c}0.0064 * * * \\
(0.0014)\end{array}$ & $\begin{array}{l}-0.002 \\
(0.002)\end{array}$ & $\begin{array}{r}0.009 * * * \\
(0.0017)\end{array}$ \\
\hline$\delta(5)$ & $\begin{array}{c}0.004^{* * *} \\
(0.0009)\end{array}$ & $\begin{array}{c}-0.002^{*} \\
(0.001)\end{array}$ & $\begin{array}{r}0.006 * * * \\
(0.0011)\end{array}$ \\
\hline$\delta(6)$ & $\begin{array}{c}0.0031^{* * *} \\
(0.0006)\end{array}$ & $\begin{array}{c}0.001 \\
(0.002)\end{array}$ & $\begin{array}{r}0.004^{* * *} \\
(0.0007)\end{array}$ \\
\hline$\delta(7)$ & $\begin{array}{c}-0.0021 * * * \\
(0.0005)\end{array}$ & $\begin{array}{l}-0.0004 \\
(0.0007)\end{array}$ & $\begin{array}{c}-0.003^{* * *} \\
(0.0007)\end{array}$ \\
\hline$\delta(8)$ & $\begin{array}{c}-0.0013 * * * \\
(0.0005)\end{array}$ & $\begin{array}{c}-0.0003 * * * \\
(0.00006) \\
\end{array}$ & $\begin{array}{c}-0.002 * * * \\
(0.0007) \\
\end{array}$ \\
\hline \multicolumn{4}{|l|}{ Cosine-terms (e-3) } \\
\hline$\varphi(1)$ & $\begin{array}{l}0.08^{* * *} \\
(0.0148)\end{array}$ & $\begin{array}{c}-0.015 \\
(0.0428)\end{array}$ & $\begin{array}{l}0.11^{* * *} \\
(0.0182)\end{array}$ \\
\hline$\varphi(2)$ & $0.03^{* * *}$ & -0.006 & $0.042 * * *$ \\
\hline \multirow{2}{*}{$\varphi(3)$} & $\begin{array}{l}(0.0054) \\
0.013 * * *\end{array}$ & $\begin{array}{c}(0.0085) \\
-0.004\end{array}$ & $\begin{array}{r}(0.0067) \\
0.017 * * * *\end{array}$ \\
\hline & $(0.0024)$ & $(0.0055)$ & $(0.0027)$ \\
\hline \multirow{2}{*}{$\varphi(4)$} & $0.004 * * *$ & -0.001 & $0.005^{* * *}$ \\
\hline & $(0.0008)$ & $(0.0010)$ & $(0.0009)$ \\
\hline \multirow{2}{*}{$\varphi(5)$} & 0.0004 & -0.0001 & 0.0002 \\
\hline & $(0.0057)$ & $(0.0003)$ & $(0.0009)$ \\
\hline$\varphi(6)$ & $\begin{array}{c}-0.003^{* * *} \\
(0.0008)\end{array}$ & $\begin{array}{c}-0.001 \\
(0.0077)\end{array}$ & $-0.003 * * *$ \\
\hline$\omega(7)$ & $-0.001^{* *}$ & 0.001 & $-0.002^{* * *}$ \\
\hline & $(0.0005)$ & $(0.0018)$ & $(0.0008)$ \\
\hline$\varphi(8)$ & 0.0002 & 0.002 & -0.0001 \\
\hline Interest differentials (e & $(0.0004)$ & (0.0035) & $(0.0005)$ \\
\hline$n(1)$ & $-0.14 * * *$ & $-0.007^{*}$ & -0.002 \\
\hline & $(0.014)$ & $(0.0036)$ & $(0.0030)$ \\
\hline$\eta(2)$ & $0.57 * *$ & 0.55 & -0.0003 \\
\hline & $(0.2591)$ & (3.438) & $(0.0050)$ \\
\hline$\eta(3)$ & $\begin{array}{c}-0.36^{*} \\
(0.2118)\end{array}$ & $\begin{array}{c}-0.48 * * * \\
(0.0918)\end{array}$ & $\begin{array}{c}0.003 \\
(0.0029)\end{array}$ \\
\hline Interventions (e-6) & & & \\
\hline$\gamma(0)$ & -0.07 & $-0.33 * * *$ & 0.03 \\
\hline & $(0.0680)$ & $(0.0636)$ & $(0.1035)$ \\
\hline$\gamma(1)$ & 0.07 & 0.01 & 0.11 \\
\hline & $(0.0700)$ & $(0.1250)$ & $(0.0909)$ \\
\hline$\gamma(2)$ & $\begin{array}{l}0.08 \\
0.0899)\end{array}$ & 0.08 & 0.09 \\
\hline$v(3)$ & -0.04 & $\begin{array}{l}-0.09 \\
-0.1201)\end{array}$ & -0.03 \\
\hline$\gamma(0)$ & $(0.0755)$ & $(0.0776)$ & $(0.0938)$ \\
\hline$\gamma(4)$ & -0.06 & $-0.13^{*}$ & -0.03 \\
\hline & $(0.0769)$ & $(0.0823)$ & $(0.0968)$ \\
\hline$\gamma(5)$ & 0.07 & -0.004 & 0.10 \\
\hline$\gamma(6)$ & $\begin{array}{l}(0.0005) \\
-0.05\end{array}$ & $\begin{array}{l}(0.0098) \\
-0.18^{* * * *}\end{array}$ & $\begin{array}{l}(0.1020) \\
-0.004\end{array}$ \\
\hline & $(0.0794)$ & $(0.0690)$ & $(0.1)$ \\
\hline
\end{tabular}




\begin{tabular}{|l|ccc|}
\hline \multicolumn{2}{|l|}{ Statistics } \\
\hline$R^{2}$ & 0.11 & 0.01 & 0.12 \\
\hline F-statistic for all variables jointly are 0 & 329 & 7 & 304 \\
\hline \\
NOTES: \\
(a) * Denotes significance at 90\%, ** Denotes significance at 95\%, *** Denotes significance at \\
$99 \%$. \\
(b) Standard Errors in ( ) below the point estimates; lags in ( ) in Variable Names \\
(c) The dependent variable is the absolute residual from the auxiliary regression, equation (1). \\
(d) The independent variables are normalizing constants, a realized volatility measure, \\
trigonometric terms, the EUR-DKK interest rate differential, and interventions. \\
\end{tabular}




\begin{tabular}{|c|c|c|c|}
\hline \multicolumn{4}{|c|}{ TABLE 5: HAC Estimation of Equation (1): Mean Equation } \\
\hline & Full-sample & Sub-sample I & Sub-sample II \\
\hline \multicolumn{4}{|l|}{ Interventions (e-6) } \\
\hline$\gamma(0)$ & $-0.12^{*}$ & $-0.28 * * *$ & -0.07 \\
\hline & $(0.0706)$ & $(0.00729)$ & $(0.0875)$ \\
\hline$\gamma(1)$ & $-0.18 * * *$ & $-0.26 *$ & $-0.18 * *$ \\
\hline$\gamma(1)$ & $(0.0776)$ & $(0.1857)$ & $(0.0896)$ \\
\hline$\gamma(2)$ & $0.14 *$ & 0.06 & $0.15 *$ \\
\hline & $(0.0966)$ & $(0.1714)$ & $(0.1154)$ \\
\hline$\gamma(3)$ & -0.08 & -0.02 & -0.11 \\
\hline & $(0.0666)$ & $(0.1250)$ & $(0.0880)$ \\
\hline$\gamma(4)$ & $0.16^{* * *}$ & 0.15 & $0.16^{*}$ \\
\hline$\gamma(4)$ & $(0.0690)$ & $(01220)$ & $(0.0842)$ \\
\hline$\gamma(5)$ & $0.14 *$ & -0.14 & $0.24^{* *}$ \\
\hline$\gamma(6)$ & $\begin{array}{c}(0.0897) \\
0.15^{*}\end{array}$ & $\begin{array}{c}(0.1505) \\
0.10\end{array}$ & $\begin{array}{c}(0.1076) \\
0.15^{*}\end{array}$ \\
\hline & $(0.0938)$ & $(0.0990)$ & $(0.1154)$ \\
\hline $\begin{array}{l}30 \text { min sum (e-6) of } \\
\text { intervention } \\
\text { coefficient. [Robust } \\
\text { Wald statistic] }\end{array}$ & $\begin{array}{c}0.1 \\
{[1.91]}\end{array}$ & $\begin{array}{c}-0.39 \\
{[2.04]}\end{array}$ & $\begin{array}{c}0.35 * * \\
{[6.35]}\end{array}$ \\
\hline \#Interventions & 220 & 58 & 162 \\
\hline \multicolumn{4}{|c|}{$\begin{array}{l}\text { NOTES: } \\
\text { (a) * Denotes significance at } 90 \% \text {, ** Denotes significance at } 95 \% \text {, *** Denotes } \\
\text { significance at } 99 \% \\
\text { (b) Standard Errors in ( ) below the point estimates; test statistic values in [ ]; lags in ( ) } \\
\text { in Variable Names } \\
\text { (c) The dependent variable is the first difference of the log of the daily DKK/EUR mid- } \\
\text { point exchange rate. } \\
\text { (d) The independent variable is current and lagged intervention. }\end{array}$} \\
\hline
\end{tabular}




\begin{tabular}{|c|c|c|}
\hline \multicolumn{3}{|c|}{$\begin{array}{l}\text { TABLE 6: WLS Estimation of Equation (1): Mean Equation with } 12 \text { lags of } \\
\text { Intervention }\end{array}$} \\
\hline & Sub-sample I & Sub-sample II \\
\hline \multicolumn{3}{|l|}{ Interventions (e-6) } \\
\hline$\gamma(0)$ & -0.34 & -0.08 \\
\hline$(1)$ & $\begin{array}{l}(2.615) \\
-0.25\end{array}$ & $\begin{array}{l}(0.0 / 14) \\
-0.16^{* * * *}\end{array}$ \\
\hline$\gamma(1)$ & $(0.1825)$ & $(0.0442)$ \\
\hline$\gamma(2)$ & 0.07 & 0.05 \\
\hline$\gamma(2)$ & $(0.1667)$ & $(0.0725)$ \\
\hline$\gamma(3)$ & -0.03 & -0.06 \\
\hline$\gamma(0)$ & $(0.1579)$ & $(0.0822)$ \\
\hline$\gamma(4)$ & 0.14 & $0.11^{*}$ \\
\hline & $(0.1111)$ & $(0.0714)$ \\
\hline$\gamma(5)$ & -0.15 & $0.32 * * *$ \\
\hline$\gamma(6)$ & $\begin{array}{c}(0.14 / 1) \\
0.20\end{array}$ & $\begin{array}{c}(0.0792) \\
0.12 *\end{array}$ \\
\hline$\gamma(0)$ & $(0.2899)$ & $(0.0863)$ \\
\hline$\gamma(7)$ & $0.20^{*}$ & $0.06 * *$ \\
\hline & $(0.1408)$ & $(0.0300)$ \\
\hline$\gamma(8)$ & -0.14 & -0.02 \\
\hline (0) & $(0.1176)$ & $(0.2000)$ \\
\hline$\gamma(9)$ & $\begin{array}{c}-0.09 \\
(0.1500)\end{array}$ & $(0.1220)$ \\
\hline$\gamma(10)$ & $-0.14 *$ & $\begin{array}{l}-0.06 \\
-0.0772\end{array}$ \\
\hline (11) & $\begin{array}{c}(0.103 /) \\
0.16\end{array}$ & $\begin{array}{l}(0.0 / / 2) \\
-0.001\end{array}$ \\
\hline$\gamma(11)$ & $(0.2857)$ & $(0.1111)$ \\
\hline$\gamma(12)$ & $\begin{array}{c}-0.13 \\
(0.1733)\end{array}$ & $\begin{array}{l}0.07 \\
(0.0875)\end{array}$ \\
\hline $\begin{array}{l}60 \text { min sum (e-6) of } \\
\text { intervention coefficient. } \\
\text { [Robust Wald statistic] }\end{array}$ & $\begin{array}{c}-0.05 \\
{[0.05]}\end{array}$ & $\begin{array}{c}0.4^{*} \\
{[2.75]}\end{array}$ \\
\hline \#Interventions & 58 & 162 \\
\hline \multicolumn{3}{|c|}{$\begin{array}{l}\text { NOTES: } \\
\text { (a) } * \text { Denotes significance at } 90 \%, * * \text { Denotes significance at } 95 \%, * * * \\
\text { Denotes significance at } 99 \% \\
\text { (b) Standard Errors in ( ) below the point estimates; test statistic values in [ ]; } \\
\text { lags in ( ) in Variable Names } \\
\text { (c) The dependent variable is the first difference of the log of the daily } \\
\text { DKK/EUR mid-point exchange rate. } \\
\text { (d) The independent variable is current and lagged intervention. }\end{array}$} \\
\hline
\end{tabular}




\begin{tabular}{|c|c|c|}
\hline \multicolumn{3}{|c|}{ Table 7 Overview of Exchange Rate Volatility, Fundamentals and Results across Sub-Samples } \\
\hline & Sub-Sample 1 & Sub-Sample 2 \\
\hline Exchange Rate Volatility (RV) & LOW & HIGH \\
\hline Fundamentals (F) & $\begin{array}{l}\text { MONETARY POLICY } \\
\text { UNCHANGED }\end{array}$ & $\begin{array}{l}\text { MONETARY POLICY } \\
\text { EASING }\end{array}$ \\
\hline $\begin{array}{l}\text { Intervention SALES and Fundamentals } \\
\text { (F) }\end{array}$ & $\begin{array}{l}\text { N.A. } \\
\text { (no sales; no change in F) }\end{array}$ & INCONSISTENT \\
\hline $\begin{array}{l}\text { Intervention PURCHASES and } \\
\text { Fundamentals (F) }\end{array}$ & $\begin{array}{l}\text { N.A. } \\
\text { (no change in F) }\end{array}$ & CONSISTENT \\
\hline Effectiveness of Intervention: ALL & $\begin{array}{l}\text { STATISTICALLY } \\
\text { INSIGNIFICANT }\end{array}$ & $\begin{array}{l}\text { STATISTICALLY } \\
\text { SIGNIFICANT }\end{array}$ \\
\hline $\begin{array}{l}\text { Economic Effect of } 100 \text { million EUR } \\
\text { Intervention: ALL }\end{array}$ & $\begin{array}{l}\text { STATISTICALLY } \\
\text { INSIGNIFICANT }\end{array}$ & $0.003 \%$ \\
\hline $\begin{array}{l}\text { Economic Effect of } 100 \text { million EUR } \\
\text { Intervention: SALES }\end{array}$ & $\begin{array}{l}\text { N.A. } \\
\text { (no sales) }\end{array}$ & $\begin{array}{l}\text { STATISTICALLY } \\
\text { INSIGNIFICANT }\end{array}$ \\
\hline $\begin{array}{l}\text { Economic Effect of } 100 \text { million EUR } \\
\text { Intervention: PURCHASES }\end{array}$ & $\begin{array}{l}\text { STATISTICALLY } \\
\text { INSIGNIFICANT }\end{array}$ & $0.3 \%$ \\
\hline \multicolumn{3}{|l|}{ Notes: } \\
\hline & $\begin{array}{l}\text { Sub-sample } 1 \text { run } \\
\text { December } 2004\end{array}$ \\
\hline \multicolumn{3}{|c|}{ Realized exchange rate volatility (RV) is calculated using 5-minute exchange rate returns } \\
\hline \multicolumn{3}{|c|}{$\begin{array}{l}\text { Fundamentals correspond to the direction of monetary policy based on changes in the DN policy rate (the } \\
\text { Folio rate) }\end{array}$} \\
\hline $\begin{array}{l}\text { d) An intervention sale denotes a sale } \\
\text { purchase of EUR against a sale of I }\end{array}$ & \multicolumn{2}{|c|}{ An intervention sale denotes a sale of EUR against a purchase of DKK; An intervention purchase denotes a } \\
\hline \multicolumn{3}{|c|}{$\begin{array}{l}\text { purchase of EUR against a sale of DKK } \\
\text { An intervention sale (purchase) is consistent with monetary policy tightening (easing) }\end{array}$} \\
\hline \multicolumn{3}{|c|}{ Effectiveness of intervention pertains to the cumulative effect of intervention shown in Table 3} \\
\hline h) The economic effect of interyentio & $\begin{array}{l}\text { the impact of the average cum } \\
2 \text { coefficient estimate of } 0.00 \\
\text { leads to a } 0.003 \% \text { change in th }\end{array}$ & $\begin{array}{l}\text { e effect across both intervention } \\
3 \text { displayed in Table } 3 \text { implies that } \\
\text { l of the DKK/EUR exchange rate }\end{array}$ \\
\hline \multicolumn{3}{|c|}{$\begin{array}{l}\text { h) The economic effect of intervention sales and purchases, respectively, is based on WLS estimations of the } \\
\text { cumulative effect of intervention with intervention sales and purchases entering as separate explanatory } \\
\text { variables (not shown for brevity). The sub-sample } 2 \text { economic effect associated with the cumulative effect } \\
\text { of an intervention purchase stems from a coefficient estimate of } 0.00003\end{array}$} \\
\hline i) & a statistically insignificant co & ent estimate is also labeled \\
\hline
\end{tabular}




\section{Figure $1 \quad$ DKK/EUR and Interventions}

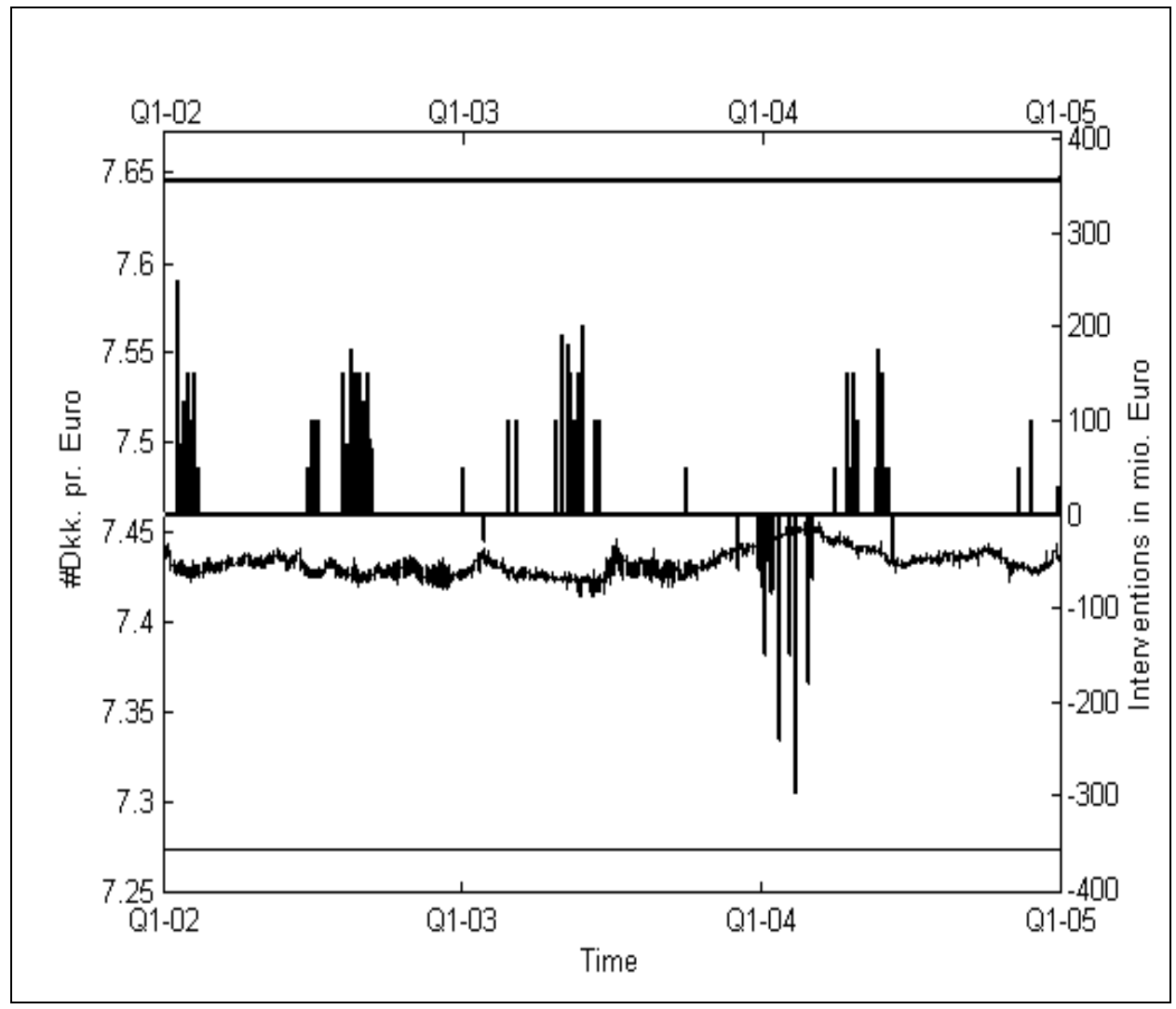

Notes: 5 min. DKK/EUR spot exchange rate returns and interventions in mill. EUR over the 1 January 2002 to 31 December 2004 period. A positive intervention corresponds to a net-purchase of EUR against a sale of DKK. The upper and lower lines are the ERM II deviation bands. Interventions are plotted against the central exchange rate at 7.46038 . 
Figure 2 Correlogram: 5 Min. Returns and Absolute Returns

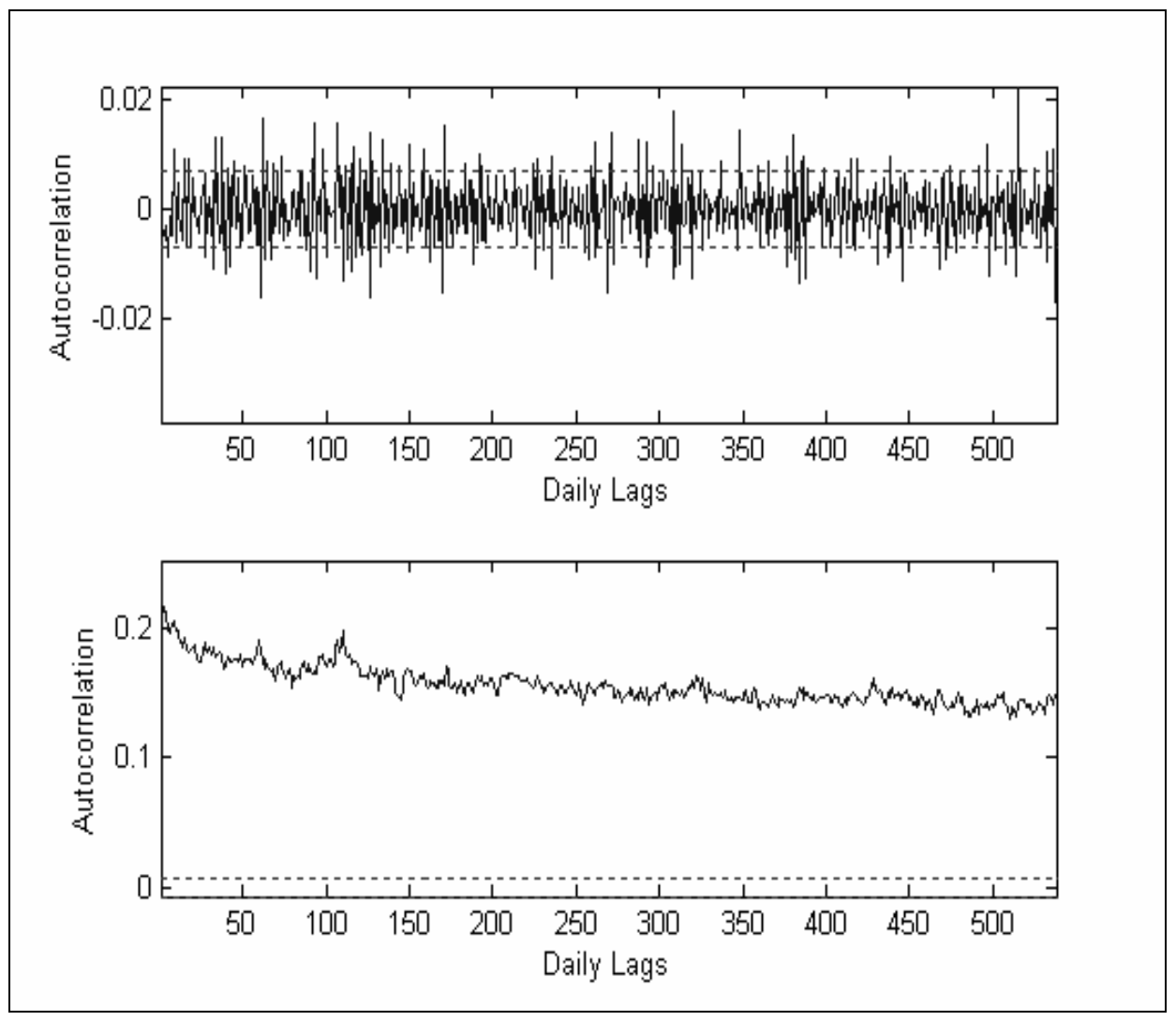

Notes: DKK/EUR spot exchange rate returns over the 1 January 2002 to 31 December 2004 period. Dotted lines correspond to confidence intervals for a white-noise process. 
Figure 3a Actual and Fitted Intraday Volatility: Sub-sample 1

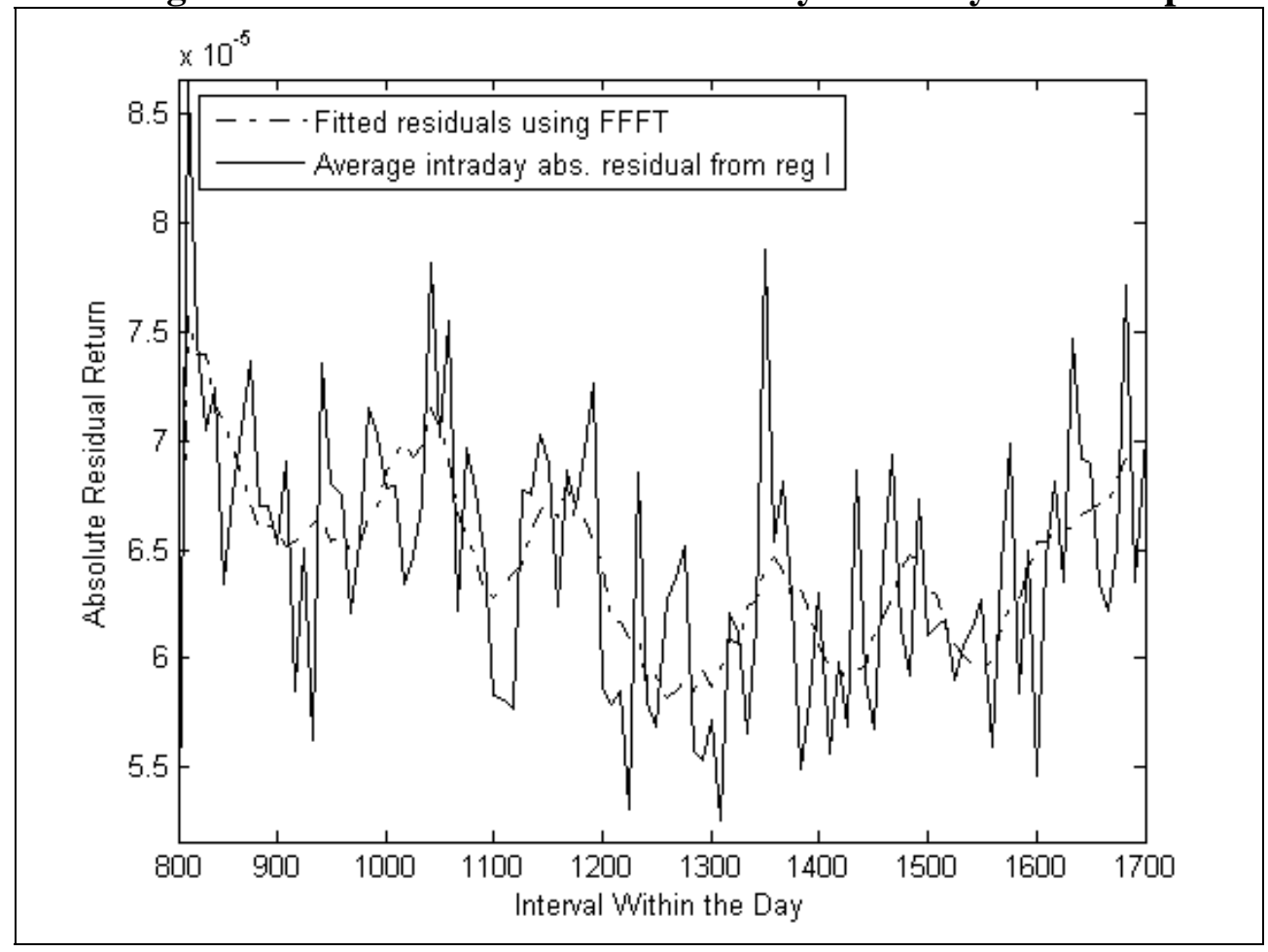

Figure 3b Actual and Fitted Intraday Volatility: Sub-sample 2

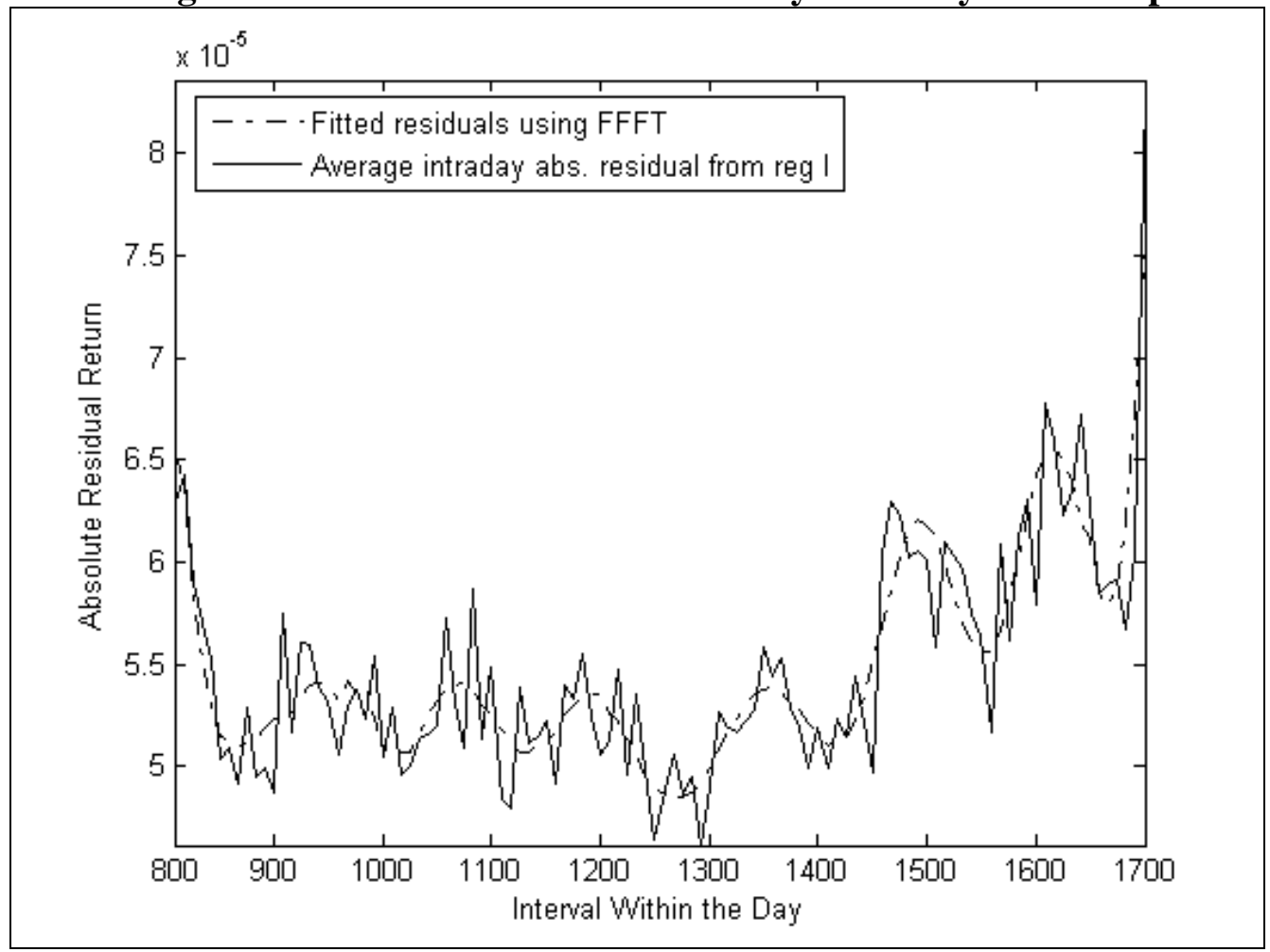

Notes: Average residuals for each 5 min. interval across 752 days against the absolute average fitted residuals from Equation 2 (dotted line). 
Figure 4 Fit With and Without the WLS Methodology

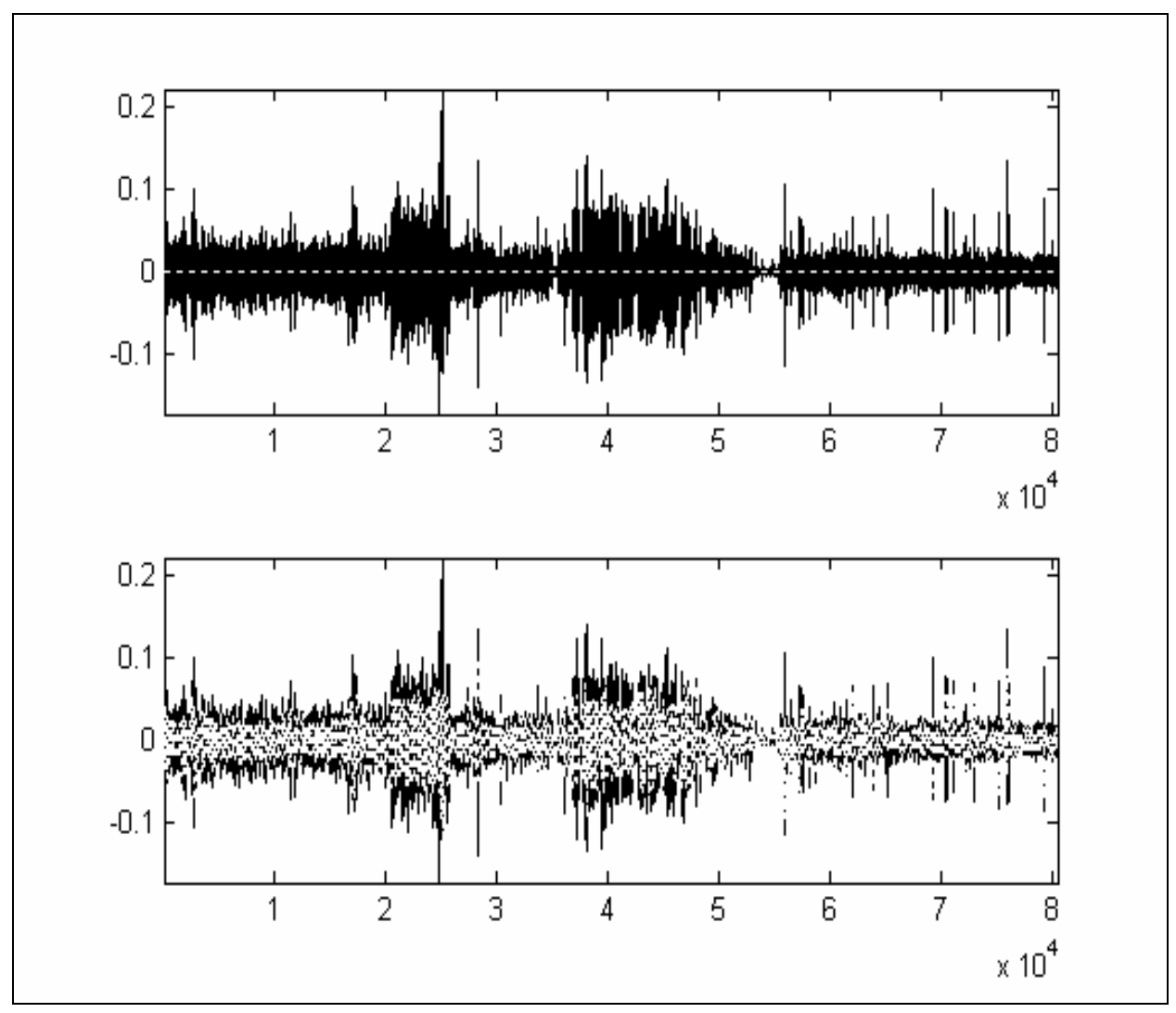

Notes: The dark observations are the raw exchange rate returns; the light observations are the fitted exchange rate returns. The figure at the top plots the fitted returns from the initial estimation of Equation (1).The lower graph shows the fitted returns from the WLS procedure of Equations (1) and (2). 
Figure 5 RV Using 5 Minute Returns

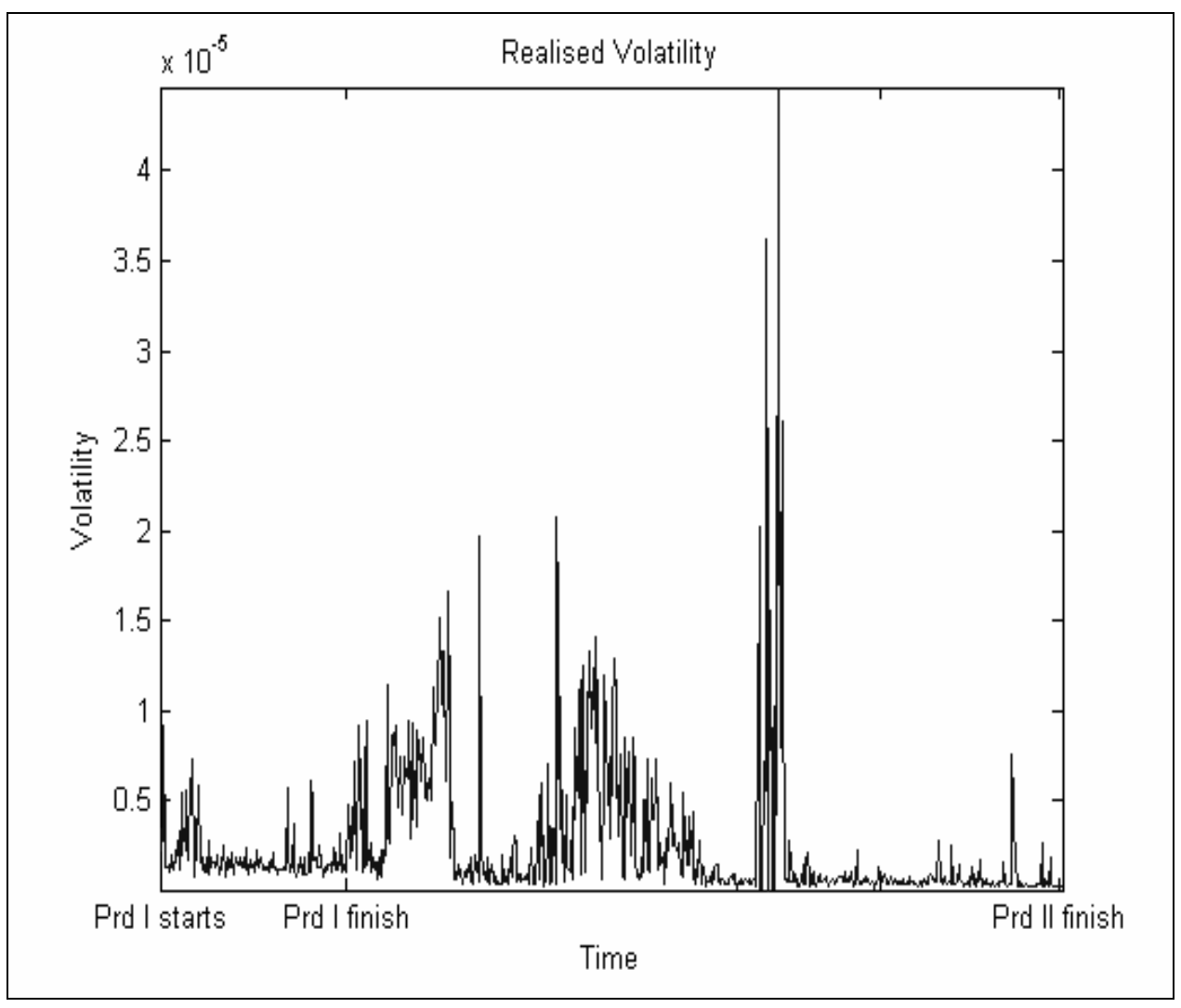

Notes: The figure shows realized volatility for the DKK/EUR exchange rate over the 1 January 2002 to 31 December 2004 period. The realized volatility is calculated as the average of the sum of the squared returns across each day in the sample. 
Figure 6 Mean Exchange Rate Return Prior to Intervention

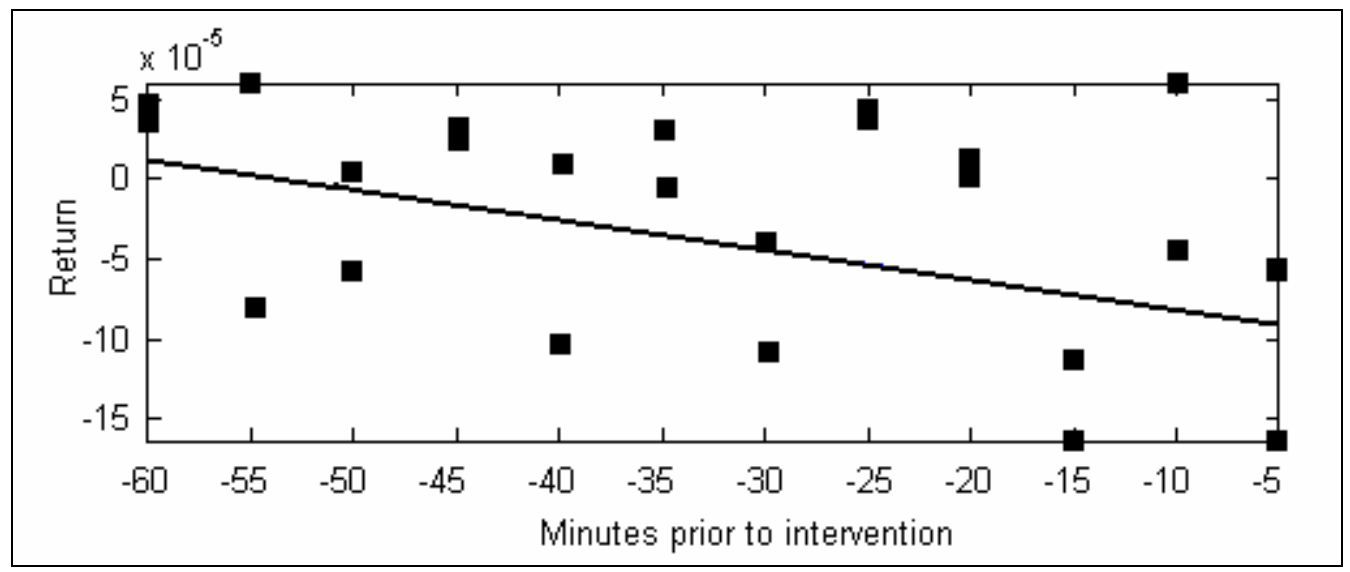

Notes: The figure shows the average unconditional change in the 5-minute exchange rate return across the 60 minutes preceding interventions (returns are normalized to allow for an aggregation of both positive and negative interventions). 